\title{
Air Ingress Benchmarking with Computational Fluid Dynamics Analysis
}

\author{
Andrew C. Kadak \\ Department of Nuclear Engineering \\ Massachusetts Institute of Technology \\ Tieliang Zhai \\ Graduate Student \\ Department of Nuclear Engineering \\ Massachusetts Institute of Technology

\section{2nd International Topical Meeting on} \\ High Temperature Reactor Technology \\ Institute of Nuclear and New Energy Technology \\ Friendship Hotel, Haidian District \\ Beijing, China
}

September 22-24, 2004

\begin{abstract}
Air ingress accident is a complicated accident scenario that may limit the deployment of hightemperature gas reactors. The complexity of this accident scenario is compounded by multiple physical phenomena that are involved in the air ingress event. These include diffusion, natural circulation, and complex chemicals reaction with graphite and oxygen. In an attempt to better understand the phenomenon, the FLUENT-6 computational fluid dynamics code was used to assess two air ingress experiments. The first was the Japanese series of tests on the reference performed in the early 1990's by Takeda and Hishida. These separate effects tests were conducted to understand and model the a multi-component experiment in which all three processes were included with the introduction of air in a heated graphite column. MIT used the FLUENT code to benchmark these series of tests with quite good results. These tests are generically applicable to prismatic reactors and the lower reflector regions of pebble-bed reactors. The second series of tests were performed at the NACOK facility for pebble bed reactors as reported by M. B. Kuhlmann in 1999. This tests were aimed at understanding natural circulation of pebble bed reactors by simulating hot and cold legs of these reactors. The FLUENT code was also successfully used to simulate these tests. The results of these benchmarks and the findings will be presented.
\end{abstract}




\section{Air Ingress Benchmarking with Computational Fluid Dynamics Analysis}

\section{Introduction}

The safety of high temperature helium cooled gas reactors is generally accepted by the scientific community. It has been accepted that these reactors are not susceptible to core melt accidents and do not require complex emergency core cooling systems for the safety of the plant. The only accident scenario that raises questions about the overall safety is the air ingress accident in which air enters the reactor system through a break in the primary circuit. This air reacts with hot graphite at temperatures ranging from 500 to $1100 \mathrm{C}$ resulting in chemical reactions that produce both $\mathrm{CO}$ and $\mathrm{CO}_{2}$ in several types of exothermic and endothermic reactions. The key challenge is this type of accident is to determine whether the graphite will burn uncontrollably or whether the reaction will be simply a chemical corrosion without the creation of a "flame". Traditional analyses have assumed a break size limited to the size of the largest "pipe" entering the reactor vessel and only one break, either at the top or bottom of the vessel occurring. Failure of the connecting "vessels" between the power conversion unit or the intermediate heat exchanger for indirect cycle plants is not assumed since these connecting "pipes" are assumed to be designed and built as reactor vessels which have an extremely low failure probability. Additionally, to terminate the accident, the supply of air is also assumed to be finite - generally limited to that found in the reactor cavity since it can be isolated after the initial pipe break and subsequent "blowdown".

These are all plausible assumptions but skepticism remains on the part of the regulator and the public regarding the air ingress accidents. Critics have pointed out that the Chernobyl reactor also contained substantial amounts of graphite that "burned". While there is much debate about whether the graphite burned or not, the issue remains to be proven for the high temperature gas reactors if they are to be deployed on a large scale.

The purpose of this paper is to summarize benchmarking work performed with the FLUENT code to model the air ingress tests performed in Japan and Germany as a prelude to using the FLUENT tool to provide an analysis of the pebble bed reactors proposed for the future. FLUENT is a computational fluid dynamics tool that can be used to model such phenomenon to provide insights as to the details of the thermal hydraulic and chemical processes underway during such an event. This understanding should provide additional confidence to the public and the regulator that this accident can be understood and effectively managed.

\section{Background}

The air ingress accident is studied in a step-by-step method. The goal of this work is to understand the phenomenon of air ingress in a graphite core and develop a methodology using computational fluid dynamics tools to more accurately model the air ingress for both pebble and prismatic cores. There are many complicated processes involved in the air ingress accident: diffusion, natural convection, dynamic and multiple chemical reactions in a complex geometry. To address the complexities of the analysis a simplified theoretical study was performed to gain 
an appreciation of the processes at work. This was followed by a CFD benchmarking program based on experimental work performed by JAERI (Japanese Atomic Energy Research Institute) in which the basic phenomenon of diffusion, natural circulation and chemical reactions are separately tested to understand main mechanisms involved in the air ingress accident. This work is applicable to prismatic reactors. To benchmark the pebble bed reactors, natural circulation experiments performed by Forschungszentrum Julich GmbH were simulated using the CFD code, FLUENT 6.1 to develop a CFD method for the analysis of the air ingress accidents in the pebble bed plants.

There are gaps in the detailed understanding of air ingress accident progression. While experiments have been done in the past, none have been conclusive regarding the potential for burning of graphite in actual reactor conditions. For the hypothetical accident study of a complete rupture of the coaxial hot gas duct, an experimental apparatus named NACOK (Naturzug im Core mit Korrosion) in KFA (Jülich Research Center, Germany), and another in JAERI (Japan Atomic Energy Research Institute) had been set up to study the ingress of air into the core as a result of natural circulation. Some initial experimental and theoretical studies have been done to investigate the air ingress phenomena and develop the passive safety technology for dealing with air ingress and graphite corrosion. Although the HTGR in JAERI has a prismatic core structure, which is different from that of MPBR, the research on this reactor has provided an additional source of information for understanding the fundamental phenomenon for all such high temperature graphite reactors.

Except for some theoretical studies on the physical processes, a sufficiently detailed and realistic study could not be found for this challenging problem in which many complicated phenomena are involved, such as mass transfer, chemical reactions, and heat transfer by conduction, natural convection and radiation. Most of the analysis on real reactors, Fort. St. Vrain, HTR-10 in China and the proposed pebble bed plant in South Africa, the analysis assumes gross corrosion properties for graphite and a limited supply of air available to assess how much graphite is consumed. Once all the air contained in the reactor cavity is consumed, the accident is assumed to be terminated. This analysis typically shows a limited quantity of graphite consumed which is confined to the graphite lower reflector, limited temperature rise in the fuel which is still below the peak temperatures allowable and no fuel interaction with the oxygen since essentially all the oxygen is consumed in the lower reflector. This work is intended to contribute towards improving the understanding of processes taking place during air ingress accidents. The objective of this aspect of the thesis will be to develop a fundamental understanding of key air ingress variables leading to the development of a model to analyze the consequences of the event.

In order to develop such detailed understanding, a Computational Fluid Dynamics (CFD) computer code is employed to model the complex fluid dynamics and chemical processes in such an event. The code chosen for this analysis is, it is important to benchmark the FLUENT 6 code[1][2] which has recently been upgraded to handle such chemical reactions. The challenge of this aspect of the thesis is to develop a benchmarked capability to model the fundamental processes underway using FLUENT 6.0.

There are two series of experiments that have been conducted on air ingress which have been published: 
The first is done in Japan by JAERI in which a series of three experiments were conducted in sequential order to develop a fundamental understanding of the three key phenomenon [3] [4] [5]:

a. Pure diffusion in an isothermal environment,

b. Diffusion and the natural convection in a thermal environment,

c. Diffusion, natural convection and chemical reactions in a thermal. These experiments were intended to simulate the environment in prismatic reactors.

The second series of air ingress tests were conducted in Germany at the Juelich Research Center. These tests were performed at the NACOK facility [6]. There were two tests conducted and a third planned. These tests were conducted in a much larger facility simulating the performance of pebble bed reactors. The first test, which is a natural circulation test, will be described in this paper.

\section{Air Ingress Accident Progression}

Figure 1 shows the air flow in an air ingress accident. Generally, the air ingress accident can be divided into three major stages [7]:

Stage 1 is defined as the depressurization state during LOCA shown in Figure 2. In stage 2, helium gas remains in the reactor vessel under essentially atmospheric conditions as shown in Figure 3. The air/helium gas mixture in the reactor cavity has a volume concentration ratio of about 1 to 1 . This means that the gas layers become stable, because helium is lighter than an air/helium gas mixture. In addition, the buoyancy force between a high-temperature coolant passage (hot leg) and a medium-temperature passage (cold leg) in the reactor is not large enough to cause natural circulation of the gas mixture (composed of $\mathrm{N}_{2}, \mathrm{O}_{2}, \mathrm{CO}_{2}$ and $\mathrm{CO}$ ) throughout the reactor. Hence, air enters the reactor vessel mainly by molecular diffusion which is very slow process. Whatever oxygen enters the reactor, it will react with graphite components and produce $\mathrm{CO}$ and $\mathrm{CO}_{2}$. In addition, the resulting gas mixture is transported by natural convection in many local spaces inside the reactor vessel. This period may last for several hours to several hundred hours depending on different break and geometry scenarios. Although the second stage may last for a long time, the total amount of air entering the reactor in this stage is very small.

As a time passes, the density of the gas mixture in the reactor increases and the buoyancy force caused by density differences between the high-temperature and medium-temperature passages also increases. Finally, because of these buoyancy forces, natural circulation of air takes place throughout the reactor which defines stage 3 . That is, air enters the reactor from the breach of the inner tube of the primary pipe and passes through the high-temperature passage and mediumtemperature passage. It goes out from the reactor through the breach of the outer tube of the primary pipe. Figure 4 shows the flow path of the air ingress event upon onset of natural circulation.

Analyses performed by the Germans, Japanese and Chinese on their reactors have shown that this accident is manageable and does not create unacceptable consequences in terms of off-site releases, due largely to the smaller size of the break assumed and the ability to stop the air ingress within several days [8]. 
While these assumptions are quite reasonable, this paper will focus on the development of analytical tools to address the physical phenomenon in a more realistic way to understand the behavior of the complicated interactions involved using a computational fluid dynamics code (FLUENT 6) to better predict the performance of the core during the event. It is expected that the methodology developed can be used to address the phenomenological questions that will result as part of the licensing of these reactors in the future without the need to make conservative assumptions in analysis or to apply potentially non-conservative assumptions that lead to accident termination.

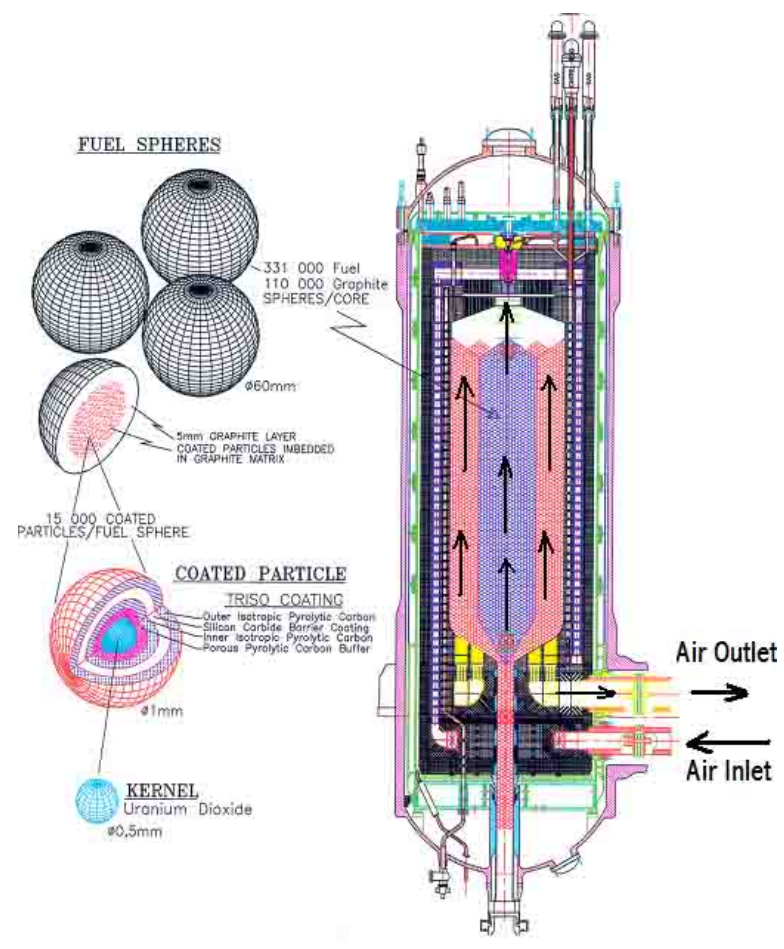

Figure 1: Air Flow in Air Ingress Accident 


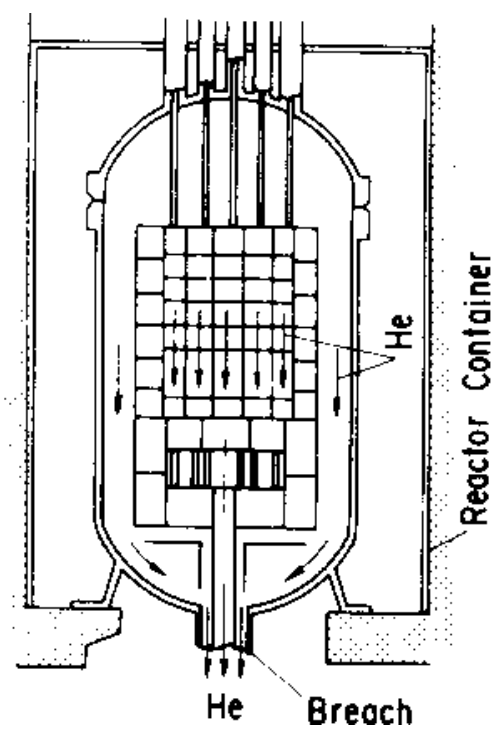

Figure 1: Stage 1: Depressurization [4]



Figure 3: Stage 2 Molecular Diffusion

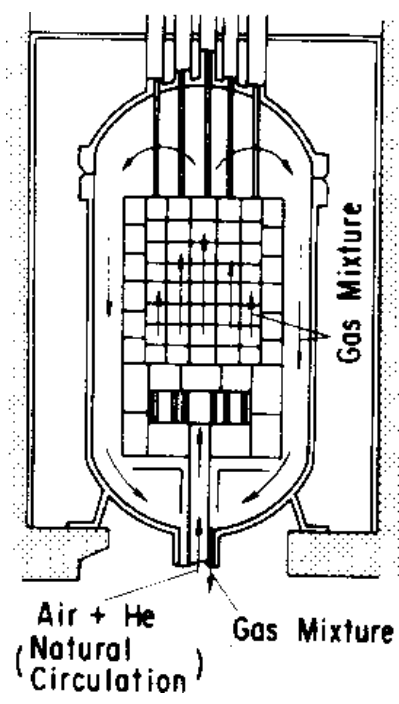

Figure 3: Stage 3 Natural Circulation

\section{Theoretical Study}

The initial theoretical study was aimed at understanding the fundamental phenomenon at work during an air ingress event. This study analyzed a simple cylinder open on the top and bottom containing a reflector on the sides and the bottom with the central region filled with pebbles to model the "chimney" effect. The HEATING 7 code was used to model the heat transfer from the reactor with simplifying assumptions that conservatively treated the expected processes. This analysis provided useful information for more detailed analysis that followed.

In this study, a scenario referred to as the "chimney effect" is assumed. Figure 5 illustrates the flow paths in the "chimney." Based on the former LOCA sensitivity study [9] the following assumptions were used in the analysis:

- The vessel is assumed to be an open-ended cylinder at both ends for initial studies.

- There is enough fresh air supply, no moisture in the air, and the inlet air temperature is $300{ }^{\circ} \mathrm{C}$ (average temperature in reactor cavity).

- The gas temperature is at all times assumed to follow the temperature of the solid structures. This is generally a good assumption because of the very slow transients and the low heat capacity of the gases.

- Did not consider the diffusion process on the pebble and reflector surface

- The initial conditions, boundary conditions, thermal properties and decay heat are same as the LOCA model.

- The only product is $\mathrm{CO}_{2}$, which is produced immediately at the graphite surface.

- No conductive cooling due to the limitation of HEATING-7. 
The air consists of only $20 \%$ (in volume) $\mathrm{O}_{2}$ and $80 \%$ (in volume) $\mathrm{N}_{2}$, which are considered as ideal gases. After the air enters into the vessel, all of the air will be consumed proportional to the contact area between the oxygen and the graphite. The experiment found that the diffusion process would dominate the chemical reaction in this air ingress accident. Due to the challenge from the diffusion, very conservatively, the resistance from the diffusion was not considered in this study.

The key parameters are shown in Table 1.

\section{Figure 5: Schematic Diagram of Air Ingress Model}

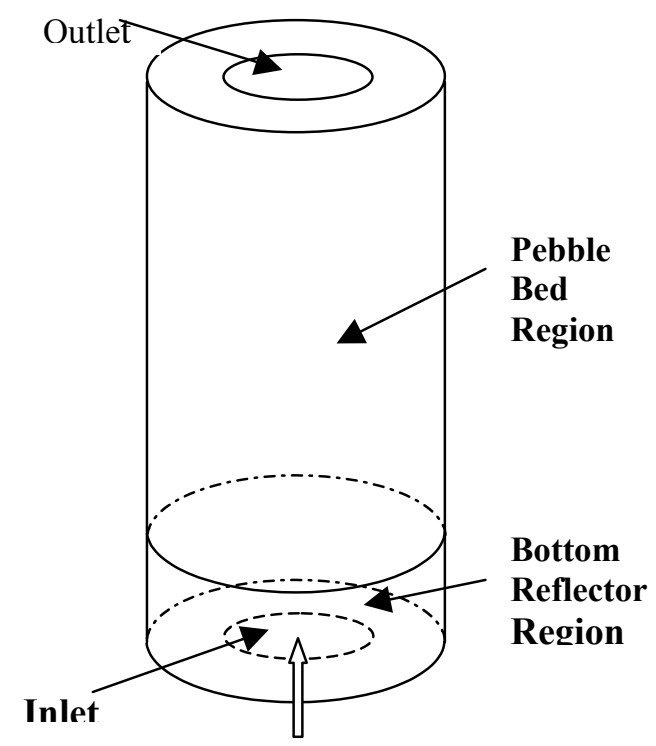

Air

In the MathCad calculation, the constants used are shown in the following table:

\begin{tabular}{|l|l|}
\hline Height of the core, $\mathrm{H}$ & $7.54 \mathrm{~m}$ \\
\hline Diameter of the core: $\mathrm{D}$ & $3.5 \mathrm{~m}$ \\
\hline Diameter of the pebbles, $\mathrm{d}$ & $0.06 \mathrm{~m}$ \\
\hline Gravitational acceleration, $\mathrm{g}$ & $9.8 \mathrm{~m} / \mathrm{s}^{2}$ \\
\hline Porosity of the pebble bed, $\varepsilon$ & 0.39 \\
\hline Temperature of the fresh air, T_air_in & $20^{\circ} \mathrm{C}$ \\
\hline Pressure of the atmosphere, $\mathrm{P} \_$atm & $1.01^{*} 10^{5} \mathrm{~Pa}$ \\
\hline
\end{tabular}

Table 1: The Parameter in the Theoretical Study

The thermal properties of the air, such as density, specific heat, conductivity and viscosity are obtained from [10]. 


\subsection{Chemical Reactions}

In contrast to its excellent thermal, mechanical and neutron physical properties, graphite possesses only a comparably low resistance to oxidizing gases. The possible chemical reactions are:

$$
\begin{array}{llr}
2 \mathrm{C}+\mathrm{O}_{2}--->2 \mathrm{CO} & (\Delta \mathrm{H}=-110.52 \mathrm{KJ} / \text { mole }) & \text { Eq. } 1 \\
\mathrm{C}+\mathrm{O}_{2}--->\mathrm{CO}_{2} & (\Delta \mathrm{H}=-393.51 \mathrm{KJ} / \text { mole }) & \text { Eq. } 2 \\
\mathrm{C}+\mathrm{CO}_{2}<--->2 \mathrm{CO} & (\Delta \mathrm{H}=+172.47 \mathrm{KJ} / \mathrm{mole}) & \text { Eq. } 3 \\
2 \mathrm{CO}+\mathrm{O}_{2}<--->2 \mathrm{CO}_{2} & (\Delta \mathrm{H}=-565.98 \mathrm{KJ} / \mathrm{mole}) & \text { Eq. } 4
\end{array}
$$

\subsection{Calculation Procedures}

The chemical reaction rate by kinetics is described as[11]:

$$
\mathrm{R}=\mathrm{K}_{1} * \exp \left(-\mathrm{E}_{1} / \mathrm{T}\right)\left(\mathrm{PO}_{2} / 20900\right)
$$

Eq. 5

When $\mathrm{T}<1273 \mathrm{~K}: \mathrm{K}_{1}=0.2475, \mathrm{E}_{1}=5710$;

When $1273 \mathrm{~K}<\mathrm{T}<2073 \mathrm{~K}, \mathrm{~K}_{1}=0.0156, \mathrm{E}_{1}=2260$;

The buoyancy is calculated using the following formula:

$$
P_{b}=\left(\rho_{c}-\rho_{h}\right) * g * \frac{H}{2}
$$

where,

$\rho_{\mathrm{c}}$ : the average density of cold leg,

$\rho_{\mathrm{h}}$ : the average density of hot leg,

g: gravitation,

$\mathrm{H}$ : the height of the reactor vessel.

For the pressure drop in the pebble bed, the following formula are adopted [12]:

$$
\Delta p=\psi \frac{H}{d} \frac{1-\varepsilon}{\varepsilon^{3}} \frac{\rho}{2} u^{2}
$$

\footnotetext{
${ }^{1} \Delta \mathrm{H}$ represents the difference between the enthalpy of the system at the beginning of the reaction compared to what it is at the end of the reaction: $\Delta \mathrm{H}=\mathrm{H}_{\text {final }}-\mathrm{H}_{\text {initial }}$ Thus: if the system has higher enthalpy at the end of the reaction, then it absorbed heat from the surroundings (endothermic reaction); if the system has a lower enthalpy at the end of the reaction, then it gave off heat during the reaction (exothermic reaction).Therefore: For endothermic reactions $\mathrm{H}_{\text {final }}>\mathrm{H}_{\text {initial }}$ and $\Delta \mathrm{H}$ is positive $(+\Delta \mathrm{H})$; For exothermic reactions $\mathrm{H}_{\text {final }}<\mathrm{H}_{\text {initial }}$ and DH is negative $(-\Delta \mathrm{H})$.
} 


$$
\psi=\frac{320}{\frac{\operatorname{Re}}{1-\varepsilon}}+\frac{6}{\left(\frac{\operatorname{Re}}{1-\varepsilon}\right)^{0.1}}
$$

Where $\psi$ is the pressure drop coefficient, which is dependent on the Reynolds number, which is defined as

$$
\operatorname{Re}=\frac{d u \rho}{\eta}
$$

$\mathrm{H}$ : the height of the pebble bed

$\mathrm{d}$ : the diameter of the pebbles

$\rho$ : the fluid density

$\eta$ : fluid dynamic viscosity

$\mathrm{u}$ : the gas velocity

$\varepsilon$ : the porosity of the pebble bed

Equation

Eq. 7 is confirmed by experiments up to $\mathrm{Re} /(1-$ $\varepsilon)=5^{*} 10^{4}$. The first term of equation represents the asymptotic solution for laminar flow, the second for turbulent flow.

The average porosity of the pebble bed $\varepsilon_{t}$ is dependent on $\mathrm{D} / \mathrm{d}$ as in the following formula (D is the diameter of the pressure vessel, and $d$ refers to the diameter of the pebbles):

$$
\varepsilon_{t}=\frac{0.78}{(D / d)^{2}}+0.375
$$

The calculation of air inlet velocity is an iterative process. For a given temperature distribution, the thermal properties of the air are calculated using the ideal gas formula. Then, the air inlet velocity is adjusted in order to balance the pressure drop and the buoyancy, and the final air inlet velocity calculated is the value at which the two forces equal each other.

\section{Results and Conclusions of the Theoretical Open Cylinder Study}

In this model, the air inlet velocity in the pebble bed reactor as a function of the graphite average temperature is studied. The calculations of the pebble bed show that the air inlet velocity does not always increase when the core is heated (Shown on 6). The air inlet velocity reaches its peak value at about $350{ }^{\circ} \mathrm{C}$. As pebble temperature increases beyond this point, the inlet air velocity goes down. This negative feedback is a very positive result for the air ingress accident study, because the core temperature is almost always well above $350^{\circ} \mathrm{C}$, which limits air ingress.

The reasons for this phenomenon are: first, with the increase of the temperature, the viscosity of the gas increases. Second, if the temperature of the air becomes higher, air density becomes lower, which would create a higher air velocity in the core (shown in

Eq. 6). However, the pressure loss is proportional to the velocity squared (shown in 
Eq. 7). In other words, the resistance increases much faster than the buoyancy with the increase of the average graphite temperature (assumed to be the gas temperature). The net effect is a reduction in air ingress velocity with higher temperature. When the air ingress is modeled for the open cylinder in the HEATING-7 analysis, the air ingress as a function of time is shown on Figure 7.

The heat generation rate of the carbon-oxygen chemical reaction was included in the HEATING7 calculations which had previously included the decay heat term. Because this is a very slow transient and because of the very low heat capacity of the gases, the gases were assumed to have a temperature distribution similar to that of the solid structure.

Figure shows the peak temperature of the core of $1663{ }^{\circ} \mathrm{C}, 21$ degree higher than the former LOCA study. The small peak temperature difference is due mainly to the low heat contribution of the chemical reactions which occur in the lower reflector. In addition, the hot-point temperatures are kept low due to the excellent conductivity of the graphite. Almost all of chemical reactions occur in the bottom reflector or in the several pebble layers of the pebble bed.

In summary, the qualitative theoretical study indicates that:

- Negative feedback mechanism: This negative feedback mechanism on air ingress velocity would reduce significantly the consequences of the air ingress accident, because the core temperature is almost always well above $350{ }^{\circ} \mathrm{C}$ in the accident process.

- No meltdown: The conservative theoretical study excludes the possibility of core meltdown. Therefore, peak temperature of core is not the primary concern for his accident as long as the peak temperature is below the silicon carbide degradation temperature.

- The contribution of heat from the chemical reaction to the peak fuel temperature is very small $\sim 20 \mathrm{C}$. Thus, chemical reactions are not expected to impact peak fuel temperatures.

- Even with an open cylinder assumption - a complete chimney - the air ingress velocity is limited to 0.025 meters $/ \mathrm{sec}(0.13 \mathrm{~kg} / \mathrm{sec})$. This small amount of air ingress may limit the potential for "burning".

- The bulk of the oxygen is consumed in the lower reflector with little interaction with the fuel pebbles.

The slow diffusion process, which may last several days, was not considered in the theoretical study, and it is assumed that the natural convection begins just after the depressurization stage, and a scenario with two-end open vessel is formed. Actually, the accident sequences and the consequences would be significantly different from that of the initial studies, and they strongly depend on the geometry of the reactor, the diffusion properties of the gases, the surface and volume reaction rates. To study these phenomena numerically, the transfer functions of momentum, energy and species must be solved in a complicated space. These requirements lead us to the adoption of the powerful CFD code which has been developed with the potential to perform a detailed study of the air ingress accident. 


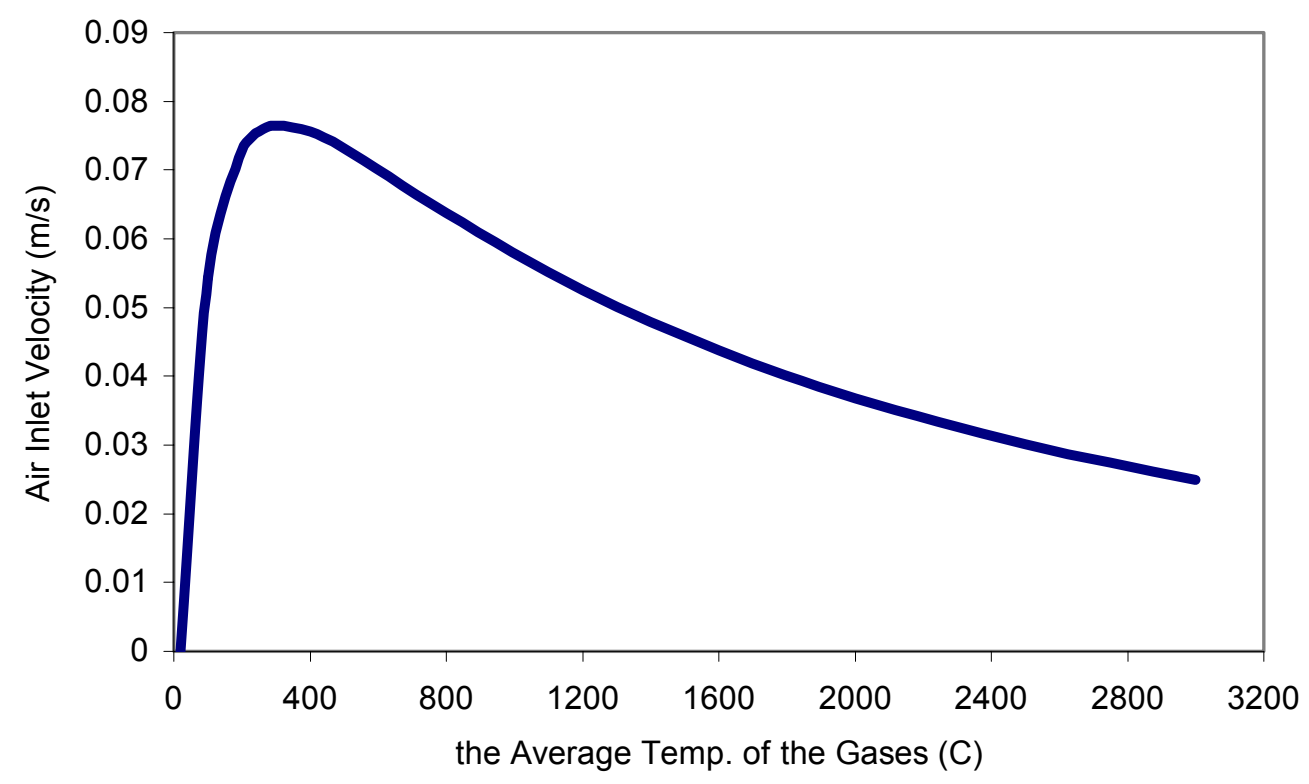

Figure 6: The Air Inlet Velocity vs. Pebble Bed's Average Temperature

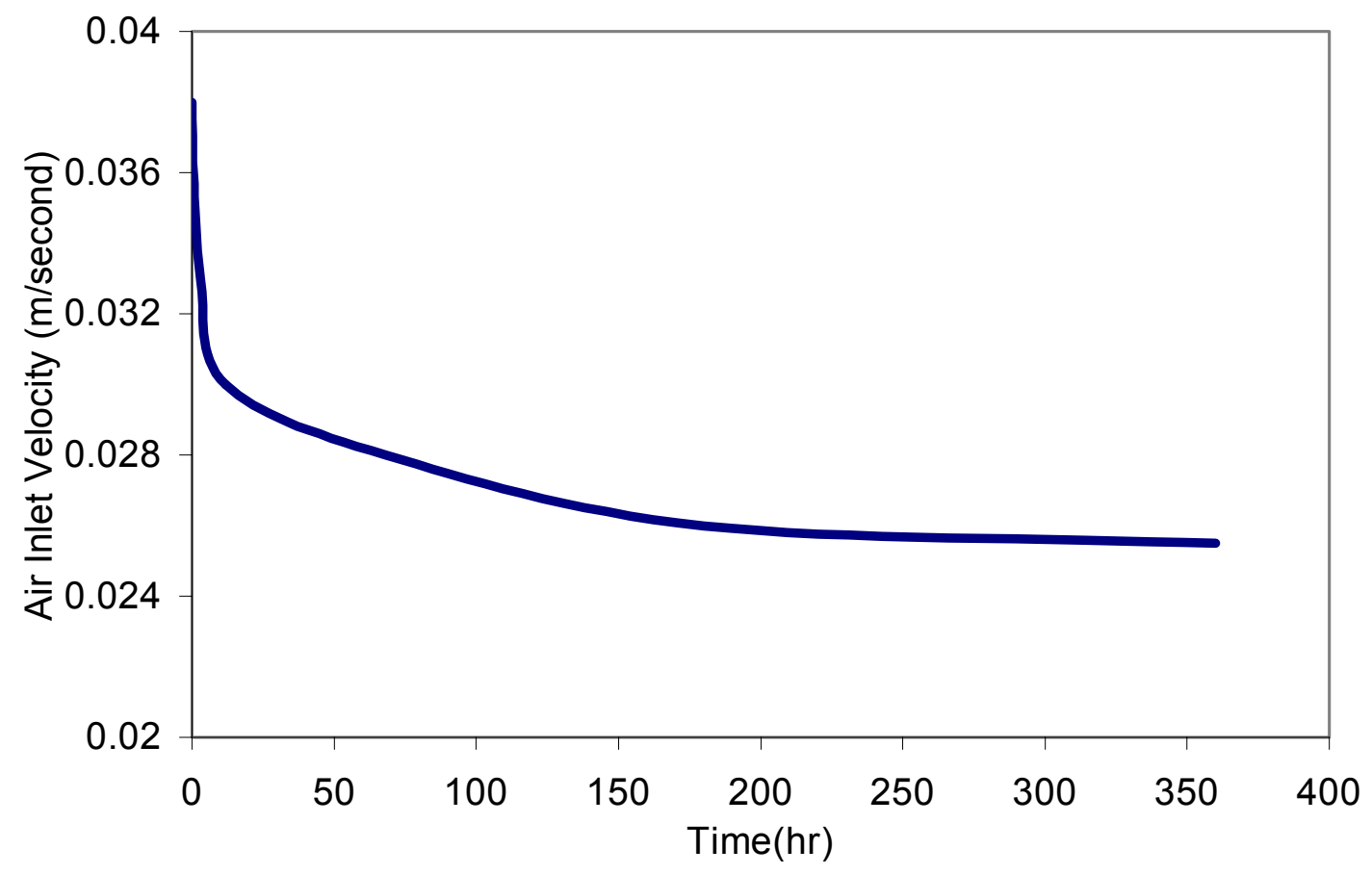

Figure 7: Air Inlet Velocity as a Function of Time 


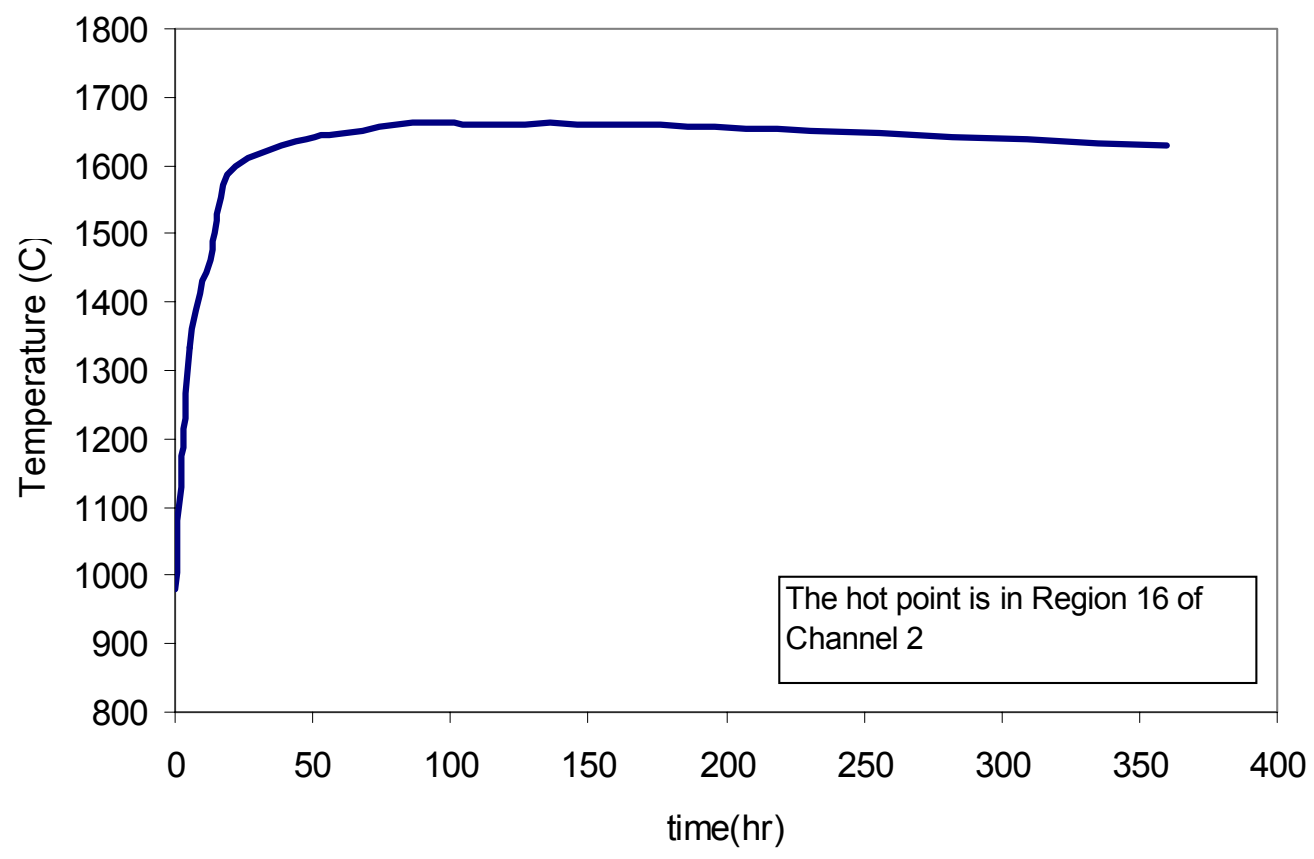

Figure 8: The Peak Temperature in the Core for Air Ingress Accident

\subsection{Computational Fluid Dynamics Studies}

As pointed out in the previous section, phenomenological understanding of the complex processes involved in air ingress requires sophisticated modeling tools. One such code is FLUENT that has recently be upgraded to handle multicomponent chemical reactions. This code will be used to develop a modeling capability for air ingress events for both pebble and prismatic type high temperature gas reactors. In order to accomplish this objective, the code methodology will be benchmarked against air ingress experiments performed in Japan and Germany. The Japanese tests were focused on prismatic reactors while the German tests examined pebble bed reactor configurations.

Based on engineering experience and previous experiments, key factors in air ingress events are:

- Onset time of air ingress post LOCA

- Temperature of the graphite (reflector and pebbles)

- Oxidation and diffusion rates for chemical reactions

- Partial pressure of oxygen and oxidation byproducts $\left(\mathrm{CO}, \mathrm{CO}_{2}\right.$,

- Velocity of air ingress

- Concentrations of $\mathrm{O}_{2}, \mathrm{CO}, \mathrm{CO}_{2}$

- Heat removal capability from the core

FLUENT 6.0 was chosen as the tool for this analysis since it has the capability to deal with these factors. 
FLUENT is the worlds' largest commercial CFD software, which has a wide range of industrial applications and world wide consulting services. Besides its capacities to model the heat transfer and mass diffusion, surface reaction model was added in its latest version - FLUENT 6.0. FLUENT is a standard CFD tool used in many complex heat transfer calculations. The FLUENT 6 version has been upgraded to allow for the introduction of chemical reactions through the use of user defined functions that can simulate graphite and oxygen reactions in addition to including all forms of heat transfer including convection. This more rigorous tool will allow more confidence in the results of air ingress analysis.

In order to understand all of the key processes (diffusion, natural convection, and chemical reactions) involved in the air ingress accident, three experiments by JAERI (Japan Atomic Energy Research Institute) and one experiment by Julich Institute of Germany will be studied with increasing complexities using the CFD code FLUENT 6.0.

\subsection{JAERI Air Ingress Experiments[3] [4] [5]}

In order to understand all of the key processes (diffusion, natural convection, and chemical reactions) involved in the air ingress accident, three experiments by JAERI (Japan Atomic Energy Research Institute) were studied with FLUENT 6.0.

\subsubsection{Isothermal JAERI Experiment - Diffusion}

\section{Experiment Description}

A rough sketch of the experimental apparatus is shown in Figure 9. The apparatus consists of a reverse U-Shape tube and a gas tank. A bent pipe connecting the two pipes is also heated. The inner diameter of the tube is $52.7 \mathrm{~mm}$.

This experiment was designed to test the first stage of air ingress - diffusion . The entire experiment was conducted at isothermal conditions at $18 \mathrm{C}$. [5] The two gases used were helium in the tube and nitrogen in the lower tank. 


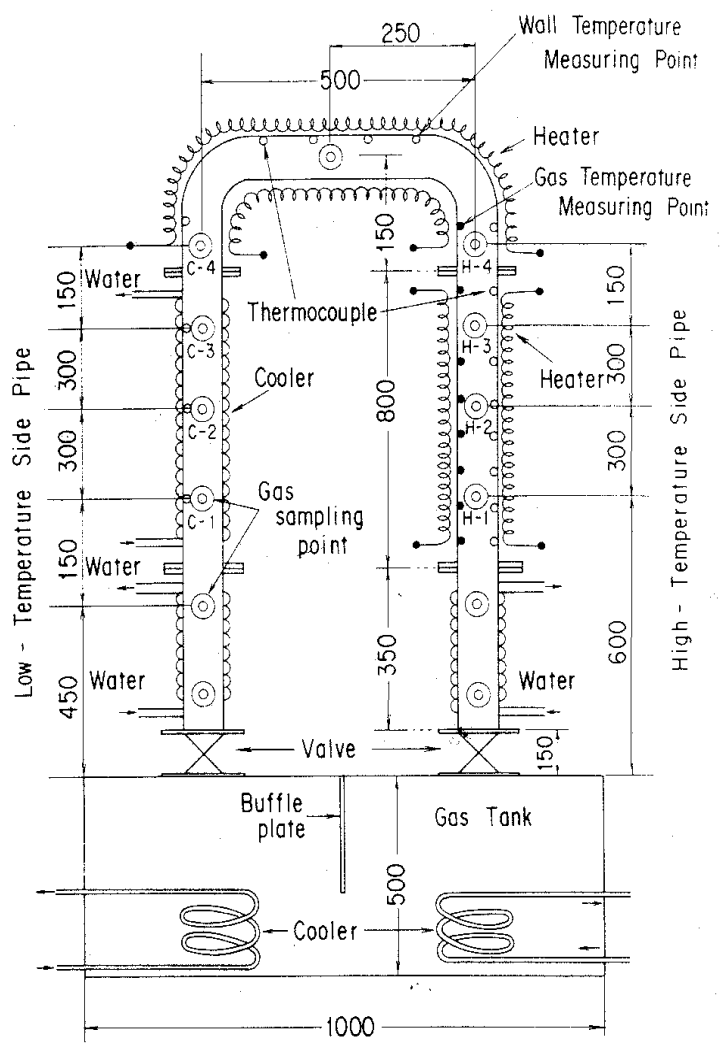

\section{Figure 9: Experimental Apparatus for Isothermal and Non-Isothermal Experiments [5]}

The experimental procedures are:

1) Close all-valves between the reverse U-Shape tube and the gas tank;

2) The tube and the gas tank is evacuated by a vacuum pump;

3) Then the tube is filled with lighter gas of $\mathrm{He}$, and heavier gas of $\mathrm{N}_{2}$ is filled in the gas tank;

4) When a steady state test condition with atmosphere pressure is reached, the ball-valves are open to simulate the pipe rupture accident.

The Figure 10 shows the geometry and mesh generation using the preprocessor GAMBIT 2.0. There are 490 hexahedral cells and 1856 mixed cells in this 3-Dimensional model. The properties of $\mathrm{He}$ and $\mathrm{N}_{2}$, such as the specific heat, conductance, density and viscosity, are all from the ideal gas database of FLUENT. The boundary condition is that all the wall temperatures are equal to the environment temperature, $18{ }^{\circ} \mathrm{C}$. Before the valve opening, there is $100 \% \mathrm{He}$ in the pipe region and $100 \% \mathrm{~N}_{2}$ in the gas tank region. In addition, no disturbance is involved in this pure diffusion process.

In this model, the ideal gas properties, including the density, conductivity, specific heat and viscocities, are adopted as the material properties. For the mass diffusivity, at single value for 18 ${ }^{\circ} \mathrm{C}$ is calculated using the following multi-component formula [14]. 


$$
D_{A-B}=\frac{10^{-7} T^{1.75}\left[\left(M_{A}+M_{B}\right) / M_{A} M_{B}\right]}{P\left(\Sigma_{A}^{1 / 3}+\Sigma_{B}^{1 / 3}\right)^{2}}
$$

Where,

$\mathrm{M}_{\mathrm{A}}$, the molecular weight of gas A;

$\mathrm{M}_{\mathrm{B}}$, the molecular weight of gas $\mathrm{B}$;

$\mathrm{P}$, the total pressure of the two gases;

$\Sigma_{\mathrm{A}}$, the diffusion volume for gas A;

$\Sigma_{\mathrm{B}}$, the diffusion volume for gas $\mathrm{B}$;

The molecular weights and the diffusion volumes, $\Sigma$, for the gases involved in the accident are shown in the following Table.

\begin{tabular}{|l|l|l|}
\hline Gas & Molecular Weight & Diffusion volumes \\
\hline $\mathrm{He}$ & 4 & 2.88 \\
\hline $\mathrm{N}_{2}$ & 28 & 17.9 \\
\hline
\end{tabular}

Table 2: The Molecular Weight and Diffusion Volume



Figure 10: The Structured Meshes for Isothermal and Non-Isothermal Experiments 


\section{Results}

Figure 1111 shows the experimental and calculated mole fraction changes of $\mathrm{N}_{2}$ at various gas sampling positions for the isothermal experiment. H1, H2, H3, H4 refer to 4 points monitored in the hot leg, and C1, C2, C3, C4 refer to 4 points monitored in the cold leg. The horizontal axis expresses the elapsed time after the simulated pipe rupture. The calculation is in good agreement with the experiment. As the mole fraction distribution of $\mathrm{N}_{2}$ is the same on both legs, natural convection of the gas mixture does not occur with pure diffusion being the only phenomenon of interest. This benchmarking shows that FLUENT can be used to model the stage 2 of air ingress (Diffusion). Figure 12 shows the uniform diffusion of the nitrogen in both legs as indicated by the mole fraction of nitrogen in the experimental assembly after 3 hours.

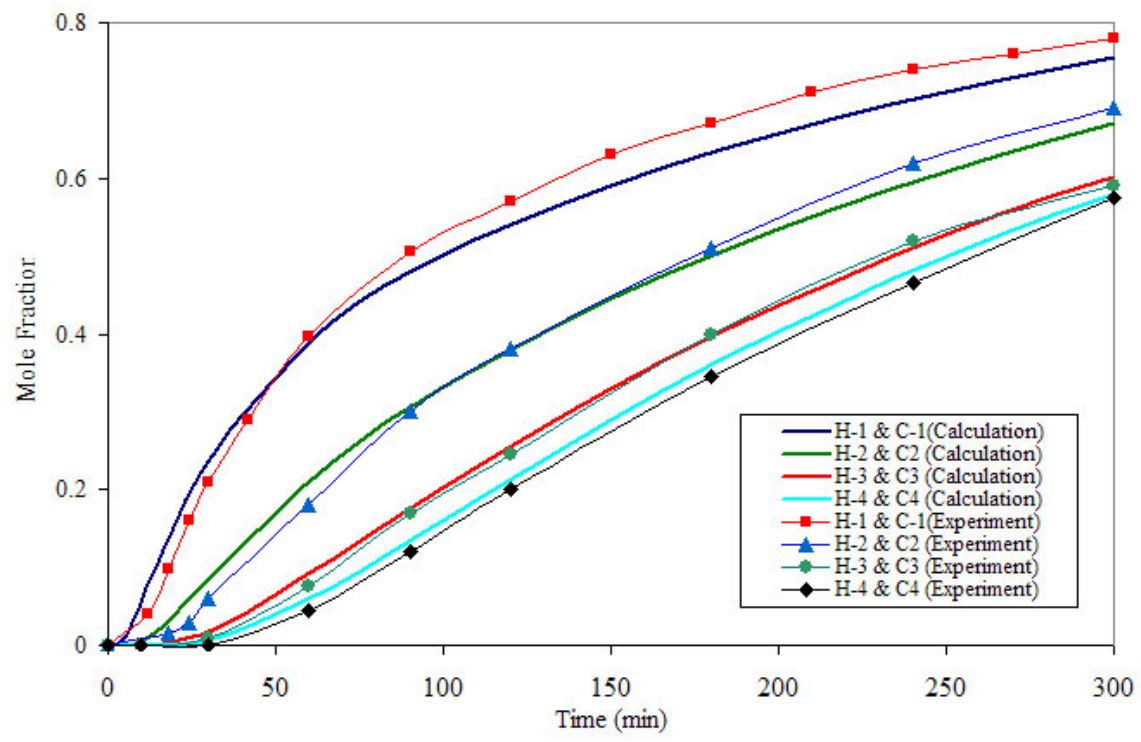

Figure 11: Mole Fraction of $\mathbf{N}_{2}$ Benchmarking of the Isothermal JAERI Experiment 


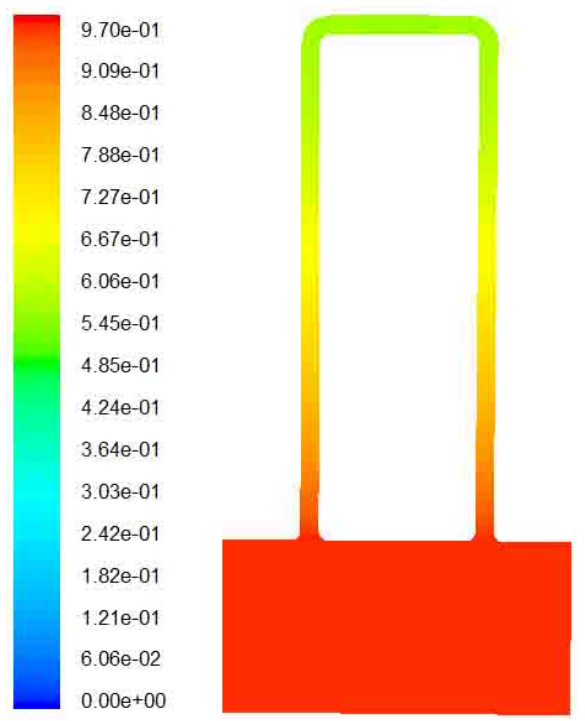

Figure 12: $\mathrm{N}_{2}$ Mole Fraction Contour $(t=180 \mathrm{~min})$

\subsubsection{JAERI Non-Isothermal Experiment}

\section{Experiment Description [3]}

The non-isothermal experiment is similar to the isothermal experiment except that the objective of this experiment is to provide a temperature gradient between the hot and cold legs to assess the onset of natural circulation. Thus, in addition to modeling the early stage diffusion of nitrogen into the helium, a temperature difference enhances the diffusion process allowing for density differences in each of the legs which ultimately creates a mechanism for natural circulation.

In the Non-Isothermal experiment, the same facility as the Isothermal experiment is used, but the pipes are heated and maintained constant temperature for every segment. The longitudinal average temperature $\mathrm{T}$ over each region is, respectively, $\mathrm{T}_{1}=19.3{ }^{\circ} \mathrm{C}, \mathrm{T}_{2}=19.3{ }^{\circ} \mathrm{C}, \mathrm{T}_{3}=256{ }^{\circ} \mathrm{C}$, $\mathrm{T}_{4}=154{ }^{\circ} \mathrm{C}, \mathrm{T}_{5}=124{ }^{\circ} \mathrm{C}, \mathrm{T}_{6}=59{ }^{\circ} \mathrm{C}, \mathrm{T}_{7}=26.3{ }^{\circ} \mathrm{C}, \mathrm{T}_{8}=17.7{ }^{\circ} \mathrm{C}, \mathrm{T}_{9}=17.7{ }^{\circ} \mathrm{C}$ (the User Defined The temperature distribution is shown on Figure 13. 


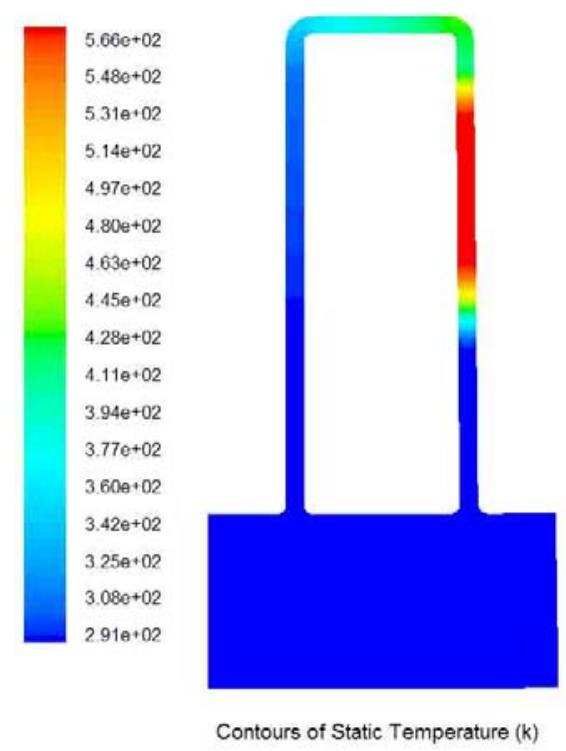

Figure 13: The Constant Temperature Boundary Condition

\section{Results}

The mole fraction change of $\mathrm{N}_{2}$ and the initiation time of the natural circulation of pure $\mathrm{N}_{2}$ agree well with the experimental results (Shown in Figures 14, 15. and 16. At some point, the density difference between the two legs is sufficiently large to develop a buoyancy force large enough to overcome the resistance to flow starting the natural circulation process. Figures 17 and 18 show two representative times that the helium is moving from the hot leg to the cold leg as the density difference between the legs is increased. The buoyancy of the hot leg is driving the helium into the cold leg and ultimately back into the nitrogen tank. At 220 minutes, natural circulation is on the verge of beginning with a very rapid flow of nitrogen from the hot leg to the cold leg in less than 1 minute.

The agreement of the FLUENT calculation with the Non-Isothermal experiment is very good, demonstrating the second phase of the air ingress phenomenon using the CFD tool. 


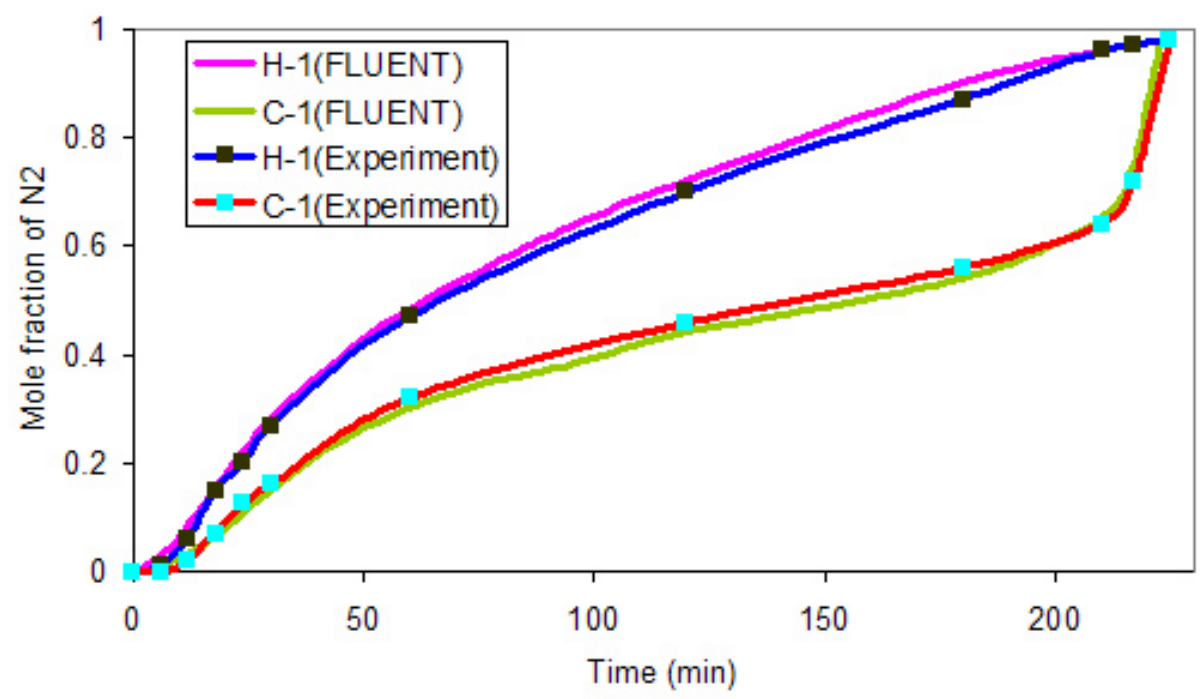

Figure 14: Comparison of mole fraction change of nitrogen between the gas sampling positions $\mathrm{H}-1$ and $\mathrm{C}-1$ in the Non-Isothermal experiment

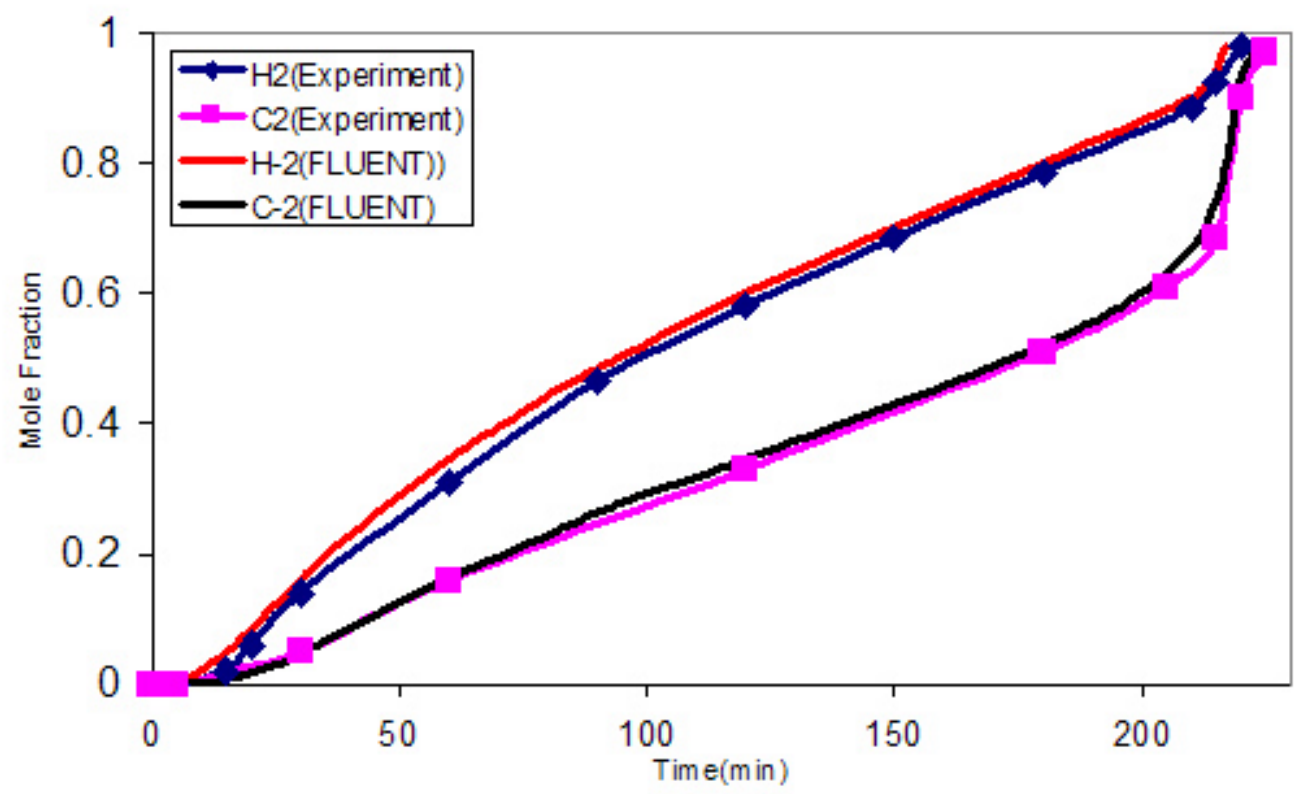

Figure 15: Comparison of mole fraction change of nitrogen between the gas sampling positions $\mathrm{H}-2$ and $\mathrm{C}-2$ in the Non-Isothermal experiment 


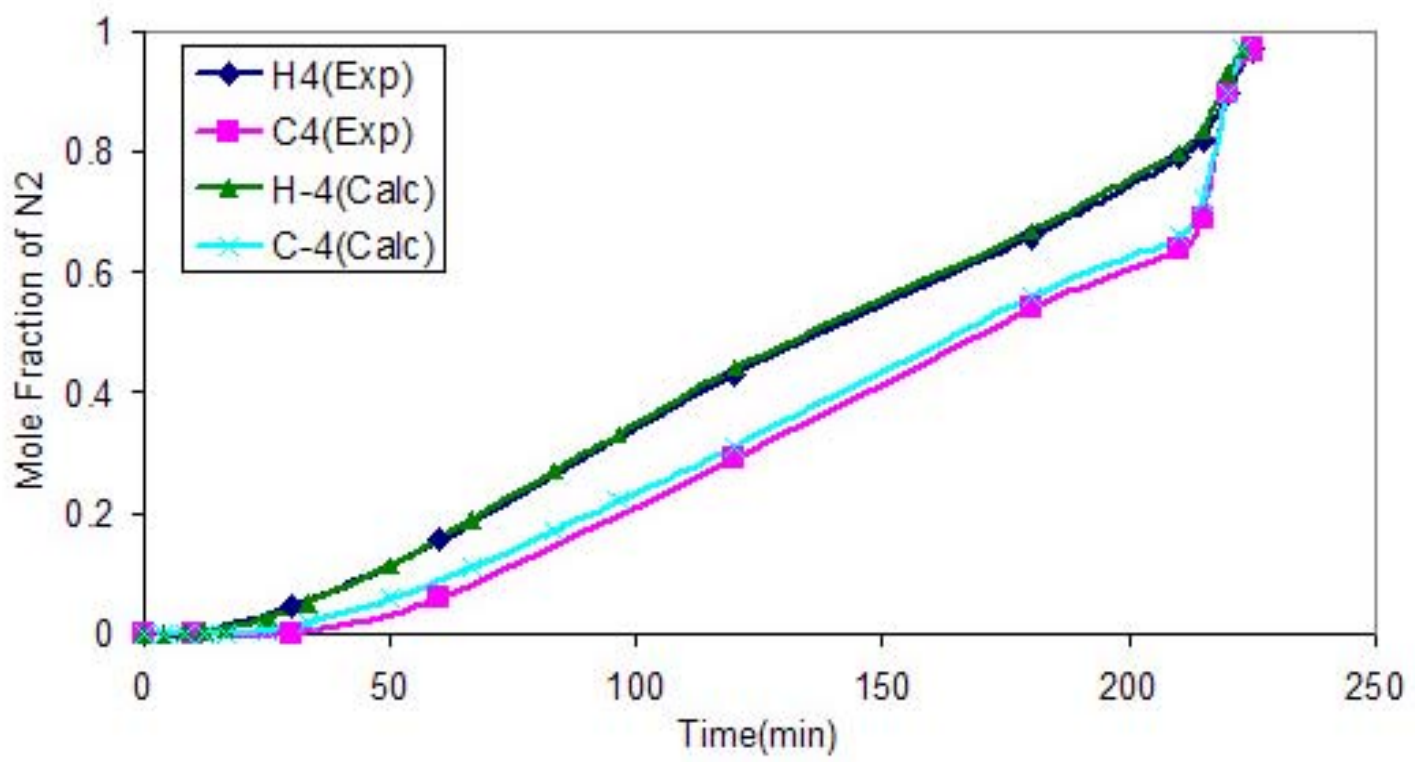

Figure 16: Comparison of mole fraction change of nitrogen between the gas sampling positions $\mathrm{H}-4$ and $\mathrm{C}-4$ in the Non-Isothermal experiment

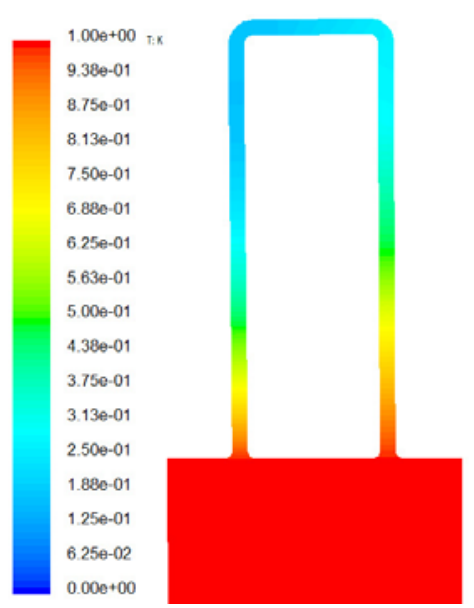

Figure 17: Nitrogen Contour $(t=75.5 \mathrm{~min})$

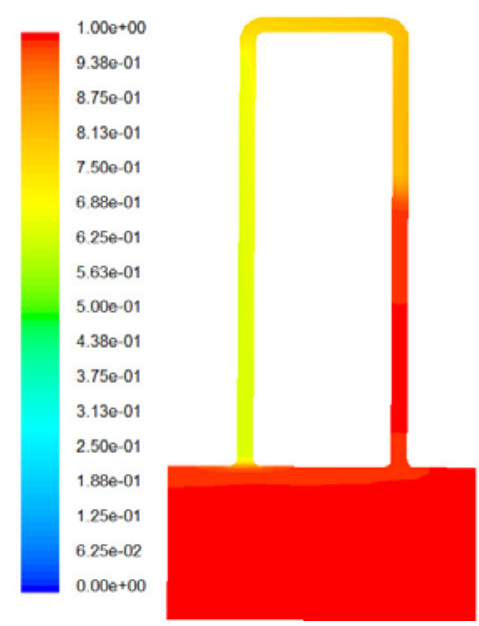

Figure 18: Nitrogen Contour $(\mathbf{t}=\mathbf{2 2 2 . 5 5})$

\subsubsection{Benchmarking of the Multi-Component Model with Chemical Reactions}

The last series of experiment conducted by JAERI is the multi-component experiment by which the combined phenomena of molecular diffusion and natural convection with a graphite oxidation reaction in a multi-component gas system were studied to investigate the process of air ingress into a reverse U-shaped tube consisting of a hot and cold leg pipe. The objectives of the multi- 
component experiment is to investigate the basic features of the flow behavior of the multicomponent gas mixture, consisting of $\mathrm{He}, \mathrm{N}_{2}, \mathrm{O}_{2}, \mathrm{CO}, \mathrm{CO}_{2}$, etc. This experiment tests all major phenomenon in an air ingress event for prismatic reactors.

\section{Experimental Apparatus [5]}

A rough sketch of the experimental apparatus can be seen in Figure19 and Figure 20. The vertical heated pipe, made of inconel, has an inner diameter of $52.5 \mathrm{~mm}$, and outer diameter of $60.3 \mathrm{~mm}$ and length of $1300 \mathrm{~mm}$. A graphite pipe is inserted into the inconel heated pipe and it measures $40.5 \mathrm{~mm}$ i.d, $52.5 \mathrm{~mm}$ o.d. and $450 \mathrm{~mm}$ in length. The graphite, IG-110, is from Toyo Tanso Co. The upper and lower inner pipes, which are also inserted in the heated pipe, are made of inconel and have the same diameter as the graphite pipe. The horizontal and bent pipes have an inner diameter of $40.5 \mathrm{~mm}$. The vertical cooled pipe measures $41.2 \mathrm{~mm}$ i.d. and $1420 \mathrm{~mm}$ in length. A gas tank, cylindrical in shape, has an i.d. of $991 \mathrm{~mm}$ and a height of $400 \mathrm{~mm}$ [5].

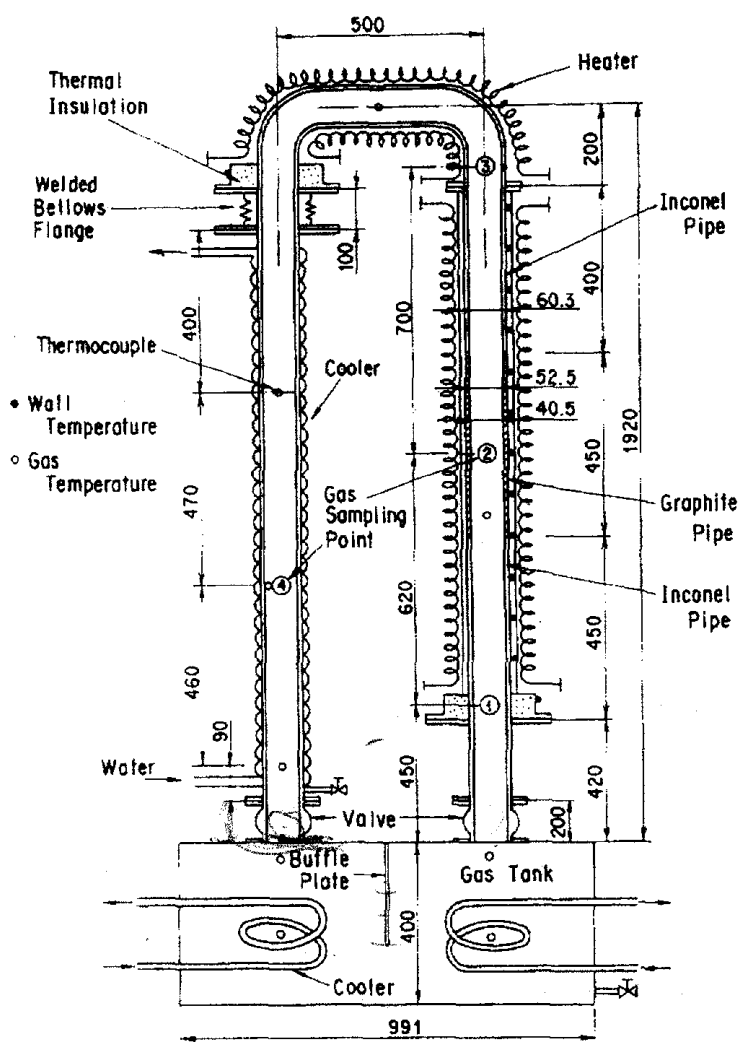

Figure 19: Experimental Apparatus for Multi-component Experiment [5] 


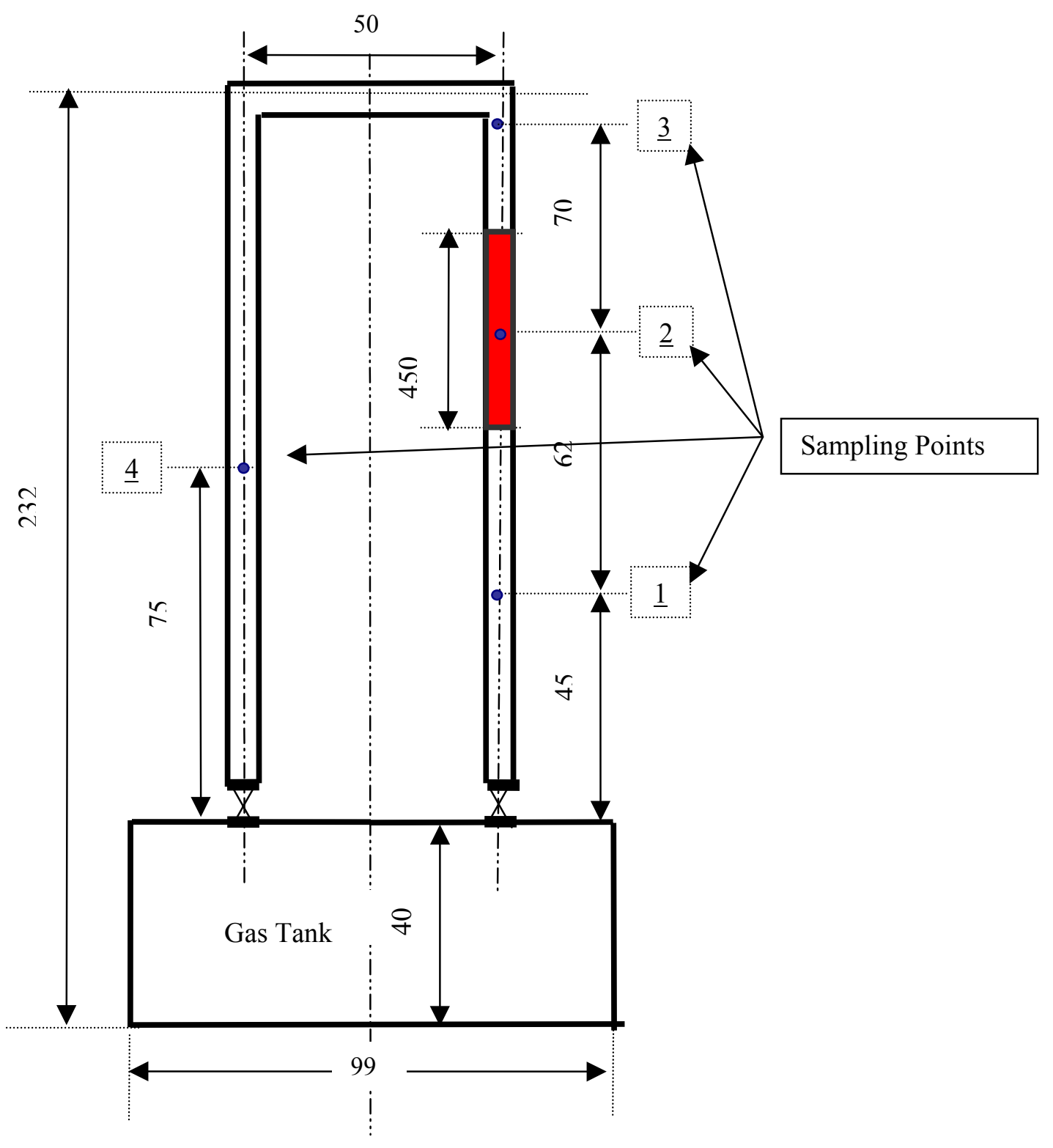

Figure 20: FLUENT Model For Multi-component Experiment

The mole fraction of each gas species and the density of the gas mixture were measured at four sampling points shown in Figure 20.

\section{Experimental Procedure [5]}

The experimental procedures are as follows: The ball valves between the reverse U-shaped tube and the gas tank were closed and the tube was evacuated using a vacuum pump. Helium and air was injected into the tube and the gas tank, respectively. Then, the high-temperature side pipe and the connecting pipe were heated from about $400{ }^{\circ} \mathrm{C}$ to $800{ }^{\circ} \mathrm{C}$ (the longitudinal average temperature of the high-temperature side pipe). When the temperature of the gas and the pipe wall reached a steady-state condition, the gas pressure in the reverse U-shaped tube was equalized to the atmospheric pressure by the opening a small release valve. Then, the two ball valves were open at the same time to simulate a pipe rupture accident. During the experiment, the temperature change of the pipe wall was held within $\pm 2{ }^{\circ} \mathrm{C}$. 
The initial conditions for the multi-component experiment are: the total pressure is equal to the atmosphere pressure, no gas flow before the opening of the valves, there is $100 \%$ helium in the pipe region above the valves, and $100 \%$ air in the tank and the pipe region below the valves. A steady state is reached for the helium in the pipes and the air in the tank. No disturbance is introduced by the opening of the valves. The temperature profile of the wall is kept constant for each segment (see Figure 21). The temperature profile was defined using User Defined Functions (UDF).
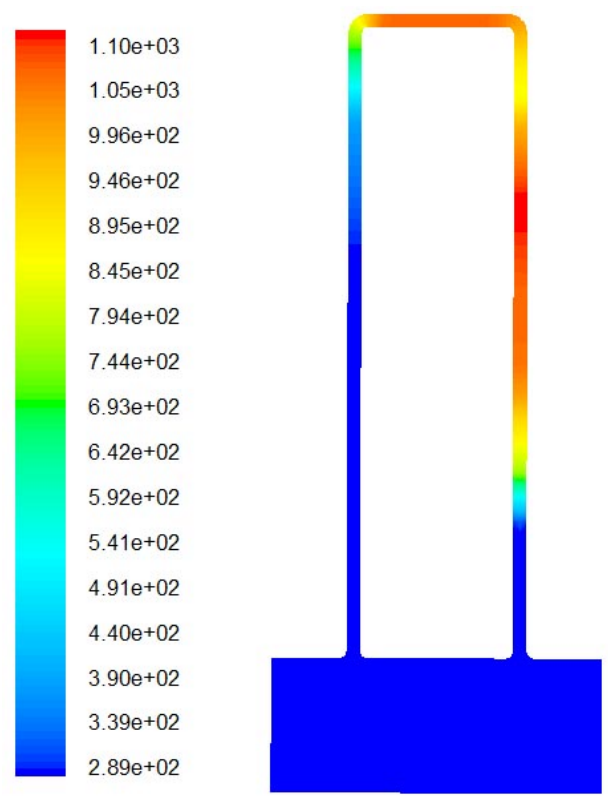

Figure 21: The Temperature Profile for the Multi-component Experiment

\section{Diffusion Coefficients}

The multi-component diffusion model is adopted for the diffusion process. For FLUENT 6.1, the definition of the multi-component diffusion coefficient could not be input directly using the formula in Eq. 10, and this formula was converted into the following form using Taylor Expansion:

$$
\mathrm{D}=\mathrm{A}_{1}+\mathrm{A}_{2} \mathrm{~T}^{1}+\mathrm{A}_{3} \mathrm{~T}^{2}+\mathrm{A}_{4} \mathrm{~T}^{3}+\mathrm{A}_{4} \mathrm{~T}^{4}
$$

There are 6 species of gases involved in the diffusion: $\mathrm{He}, \mathrm{N}_{2}, \mathrm{O}_{2}, \mathrm{H}_{2} \mathrm{O}, \mathrm{CO}, \mathrm{CO}_{2}$, therefore, 15 diffusion coefficients need to be defined. The constants of $A_{1}, A_{2}, A_{3}, A_{4}$, and $A_{5}$ are shown in Table 3. 
Table 3: The Constants to Define the Diffusion Coefficients

\begin{tabular}{|c|c|c|c|c|c|}
\hline & $\mathrm{O}_{2}-\mathrm{CO}$ & $\mathrm{O}_{2}-\mathrm{CO}_{2}$ & $\mathrm{O}_{2}-\mathrm{He}$ & $\mathrm{O}_{2}-\mathrm{H}_{2} \mathrm{O}$ & $\mathrm{O}_{2}-\mathrm{N}_{2}$ \\
\hline A1 & $-4.300 \mathrm{E}-06$ & $-3.400 \mathrm{E}-06$ & $-1.520 \mathrm{E}-05$ & $-5.600 \mathrm{E}-06$ & $-4.400 \mathrm{E}-06$ \\
\hline A2 & $3.966 \mathrm{E}-08$ & $3.146 \mathrm{E}-08$ & $1.400 \mathrm{E}-07$ & $5.147 \mathrm{E}-08$ & 4.039E-08 \\
\hline A3 & $1.492 \mathrm{E}-10$ & $1.184 \mathrm{E}-10$ & $5.266 \mathrm{E}-10$ & $1.937 \mathrm{E}-10$ & $1.520 \mathrm{E}-10$ \\
\hline A4 & $-1.658 \mathrm{E}-14$ & $-1.316 \mathrm{E}-14$ & $-5.852 \mathrm{E}-14$ & $-2.152 \mathrm{E}-14$ & $-1.689 \mathrm{E}-14$ \\
\hline \multirow[t]{2}{*}{ A5 } & $1.919 \mathrm{E}-18$ & $1.523 \mathrm{E}-18$ & $6.774 \mathrm{E}-18$ & $2.491 \mathrm{E}-18$ & $1.955 \mathrm{E}-18$ \\
\hline & & $\mathrm{CO}-\mathrm{CO}_{2}$ & $\mathrm{CO}-\mathrm{He}$ & $\mathrm{CO}-\mathrm{H}_{2} \mathrm{O}$ & $\mathrm{CO}-\mathrm{N}_{2}$ \\
\hline A1 & & $-3.400 \mathrm{E}-06$ & $-1.450 \mathrm{E}-05$ & $-5.500 \mathrm{E}-06$ & $-4.300 \mathrm{E}-06$ \\
\hline A2 & & $3.145 \mathrm{E}-08$ & $1.334 \mathrm{E}-07$ & $5.042 \mathrm{E}-08$ & 3.996E-08 \\
\hline A3 & & $1.183 \mathrm{E}-10$ & $5.019 \mathrm{E}-10$ & $1.897 \mathrm{E}-10$ & $1.503 \mathrm{E}-10$ \\
\hline A4 & & $-1.315 \mathrm{E}-14$ & $-5.578 \mathrm{E}-14$ & $-2.108 \mathrm{E}-14$ & $-1.671 \mathrm{E}-14$ \\
\hline \multirow[t]{2}{*}{ A5 } & & $1.522 \mathrm{E}-18$ & $6.456 \mathrm{E}-18$ & $2.440 \mathrm{E}-18$ & $1.934 \mathrm{E}-18$ \\
\hline & & & $\mathrm{CO}_{2}-\mathrm{He}$ & $\mathrm{CO}_{2}-\mathrm{H}_{2} \mathrm{O}$ & $\mathrm{CO}_{2}-\mathrm{N}_{2}$ \\
\hline A1 & & & $-1.210 \mathrm{E}-05$ & $-4.500 \mathrm{E}-06$ & $-3.500 \mathrm{E}-06$ \\
\hline A2 & & & $1.114 \mathrm{E}-07$ & $4.105 \mathrm{E}-08$ & 3.199E-08 \\
\hline A3 & & & 4.193E-10 & $1.545 \mathrm{E}-10$ & $1.204 \mathrm{E}-10$ \\
\hline A4 & & & $-4.660 \mathrm{E}-14$ & $-1.717 \mathrm{E}-14$ & $-1.337 \mathrm{E}-14$ \\
\hline \multirow[t]{2}{*}{ A5 } & & & $5.394 \mathrm{E}-18$ & $1.987 \mathrm{E}-18$ & $1.548 \mathrm{E}-18$ \\
\hline & & & & $\mathrm{He}-\mathrm{H}_{2} \mathrm{O}$ & $\mathrm{He}-\mathrm{N}_{2}$ \\
\hline A1 & & & & $-1.770 \mathrm{E}-05$ & $-1.480 \mathrm{E}-05$ \\
\hline A2 & & & & $1.633 \mathrm{E}-07$ & $1.366 \mathrm{E}-07$ \\
\hline A3 & & & & $6.144 \mathrm{E}-10$ & $5.139 \mathrm{E}-10$ \\
\hline A4 & & & & $-6.828 \mathrm{E}-14$ & $-5.710 \mathrm{E}-14$ \\
\hline \multirow[t]{2}{*}{ A5 } & & & & 7.903E-18 & 6.609E-18 \\
\hline & & & & & $\mathrm{H}_{2} \mathrm{O}-\mathrm{N}_{2}$ \\
\hline A1 & & & & & $-5.600 \mathrm{E}-06$ \\
\hline A2 & & & & & $5.140 \mathrm{E}-08$ \\
\hline A3 & & & & & $1.934 \mathrm{E}-10$ \\
\hline A4 & & & & & $-2.149 \mathrm{E}-14$ \\
\hline A5 & & & & & 2.488E-18 \\
\hline
\end{tabular}

The molecular weights and the diffusion volumes, $\Sigma$, for the gases involved in the accident are shown in the Table 4.

Table 5: The Molecular Weight and Diffusion Volume

\begin{tabular}{|l|l|l|}
\hline Gas & Molecular Weight & Diffusion volumes \\
\hline $\mathrm{He}$ & 4 & 2.88 \\
\hline $\mathrm{O}_{2}$ & 32 & 16.6 \\
\hline $\mathrm{N}_{2}$ & 28 & 17.9 \\
\hline $\mathrm{CO}$ & 28 & 18.9 \\
\hline $\mathrm{CO}_{2}$ & 44 & 26.9 \\
\hline
\end{tabular}




\section{Chemical Reaction Rates [5]}

The graphite oxidation reaction $\left(\mathrm{C}-\mathrm{O}_{2}\right)$ reaction $)$ and the carbon monoxide combustion $\left(\mathrm{CO}-\mathrm{O}_{2}\right.$ reaction) are taken into account. The chemical equation of the graphite reaction is expressed as [5]:

$$
\mathrm{C}+\mathrm{z} \cdot \mathrm{O}_{2} \rightarrow \mathrm{x} \cdot \mathrm{CO}+\mathrm{y} \cdot \mathrm{CO}_{2}
$$

The reaction rate is described as

$$
r_{c-o}=K_{0} \exp \left(-\frac{E_{0}}{R T}\right) p_{o_{2}}^{n}
$$

where,

$\mathrm{K}_{0}=360$, reaction constant, $\mathrm{E}_{0}=209\left[\mathrm{kJmole}^{-1}\right]$, activation energy,

$\mathrm{P}_{\mathrm{O} 2}$, the oxygen partial pressure.

The units of $\mathrm{R}, \mathrm{T}, \mathrm{r}_{\mathrm{c}-\mathrm{o}}$ and $\mathrm{P}_{\mathrm{O} 2}$ are $\left[\mathrm{Jmole}^{-1} \mathrm{~K}^{-1}\right],[\mathrm{K}],\left[\mathrm{kg} \cdot \mathrm{kg}^{-1} \mathrm{~s}^{-1}\right]$ and $[\mathrm{pa}]$, respectively. The value of the exponential index, $\mathrm{n}$, in terms of the oxygen partial pressure ranges from 0.75 to 1 for $\mathrm{PGX}^{2}$. For this type of graphite, the value used in this analysis is 1 following JAERI's recommendation [5].

The production ratio of $\mathrm{CO}$ to $\mathrm{CO}_{2}(\mathrm{x} / \mathrm{y}=\mathrm{A})$ is correlated as follows:

$$
\begin{aligned}
A & =K_{1} \exp \left(-\frac{E_{1}}{R T}\right) \\
\mathrm{K}_{1} & =7943, \\
\mathrm{E}_{1} & =78.3\left[\mathrm{kJmole}^{-1}\right], \text { activation energy, }
\end{aligned}
$$

Where $K_{1}$ is the constant and $E_{1}$ the activation energy. The reported ratios differ over a wide range because the production ratio depends on experimental conditions, such as the catalytic effects of the impurities contained in the graphite and the grade of graphite. There is no data on these effects, thus, it is assumed that the production ratio of $\mathrm{CO}$ to $\mathrm{CO}_{2}$ is constant since the wall temperature is assumed constant.

The mole number for the reaction term of $\mathrm{O}_{2}$ and for the generation term of $\mathrm{CO}$ and $\mathrm{CO}_{2}$ of 12 can be obtained from the following relation, respectively [5].

$$
z=N_{o 2}=\frac{A+2}{2(A+1)}
$$

\footnotetext{
${ }^{2}$ The name of the graphite used in the multi-component experiment.
} 


$$
\begin{aligned}
& x=N_{c o}=\frac{A}{A+1} \\
& x=N_{c o 2}=\frac{1}{A+1}
\end{aligned}
$$

Eq. 16

The chemical equation of the CO combustion is expressed as [5].

$$
\begin{array}{ll}
\mathrm{CO}+\frac{1}{2} \mathrm{O}_{2} \rightarrow \mathrm{CO}_{2} & \text { Eq. } 18 \\
\frac{d C_{c o}}{d t}=-r_{c o-o 2} \cdot C_{c o} \cdot C_{o 2}^{0.5} \cdot C_{H 2 O}^{0.5}\left[\mathrm{~mol} \cdot \mathrm{m}^{-3} \mathrm{~s}^{-1}\right] & \text { Eq. } 19 \\
\text { where, } & \text { Eq. } 20 \\
r_{c o-o 2}=K_{2} \exp \left(-\frac{E_{2}}{R T}\right) & \text { Eq. } 21 \\
C_{c o}=\frac{\rho_{c o}}{M_{c o}}=\frac{\rho \cdot \omega_{c o}}{M_{c o}} & \text { Eq. } 22 \\
C_{O 2}=\frac{\rho_{o 2}}{M_{o 2}}=\frac{\rho \cdot \omega_{o 2}}{M_{o 2}} & \text { Eq. } 23 \\
C_{c o}=\frac{\rho_{c o}}{M_{c o}}=\frac{\rho \cdot \omega_{c o}}{M_{c o}} & \text { Eq. } 24 \\
C_{H_{2} O}=C \cdot X_{H_{2} O}=\frac{\rho}{M} \cdot X_{H_{2} O} &
\end{array}
$$

Here, $\mathrm{K}_{2}=1.3 \times 10^{8}\left[\mathrm{~m}^{3} \cdot \mathrm{mol}^{-1} \cdot \mathrm{s}^{-1}\right], \mathrm{E}_{2}=126\left[\mathrm{~kJ} \cdot \mathrm{mol}^{-1}\right]$.

\section{Mesh}

A grid adaptation of FLUENT was used in this multi-component model. In the pipe and tank region near the ball valve, denser meshes are generated since the species gradients would be higher in these regions. In addition, through grid adaptation technology, the mesh regions with higher mesh densities move with the species gradient frontiers which determines the convergence speed of every time step. For the grid adaptation technology, see the Chapter 23 of Reference [2].

\section{Results}

In the transient calculation of the multi-component experiment, lower time steps, 0.001-0.01 second, are used for the initial simulation due to the higher species concentration gradients near the ball valve regions. With the decrease of the gradients, time steps are increased to 1.5 seconds. Compared with the former two cases, Isothermal and Non-Isothermal experiments, this is much more time consuming calculation since besides the heat transfer and the natural convection, 
complicated mass transport and chemical reactions are modeled in the multi-component. For detailed model summary, see [9]. Figures 22-24 show the comparisons between the calculation and the experiment for the mole fraction changes of $\mathrm{O}_{2}, \mathrm{CO}$ and $\mathrm{CO}_{2}$ at various locations in the experiment. The results show quite good agreement with experiment at the measured points for $\mathrm{O}_{2}, \mathrm{CO}$ and $\mathrm{CO}_{2}$ mole fractions. The FLUENT code also predicts well the onset of natural circulation.

Shown on Figure 22 are the point 1 mole fractions calculated compared to the experimental results for $\mathrm{O}_{2}, \mathrm{CO}$ and $\mathrm{CO}_{2}$. While the oxygen is slightly over-predicted below the heated graphite region, there is good agreement with the $\mathrm{CO}$ and $\mathrm{CO}_{2}$ mole fractions as a function of time. The onset of natural circulation is predicted to within less $10 \%$ of the actual experimental result.



Figure 22: Mole Fraction at Point-1

Shown on Figure 23 are the point 3 mole fractions just above the heated graphite zone. This figure shows that all of the oxygen is consumed in the graphite zone until natural circulation begins rapidly. This figure also shows that the predominant species at Point 3 is $\mathrm{CO}_{2}$ and that the concentration of $\mathrm{CO}$ is relatively low (less than $3 \%$ ). This potentially an important finding relative to "burning" since $\mathrm{CO}$ is subject to oxidation forming $\mathrm{CO}_{2}$ which can be considered "burning. 


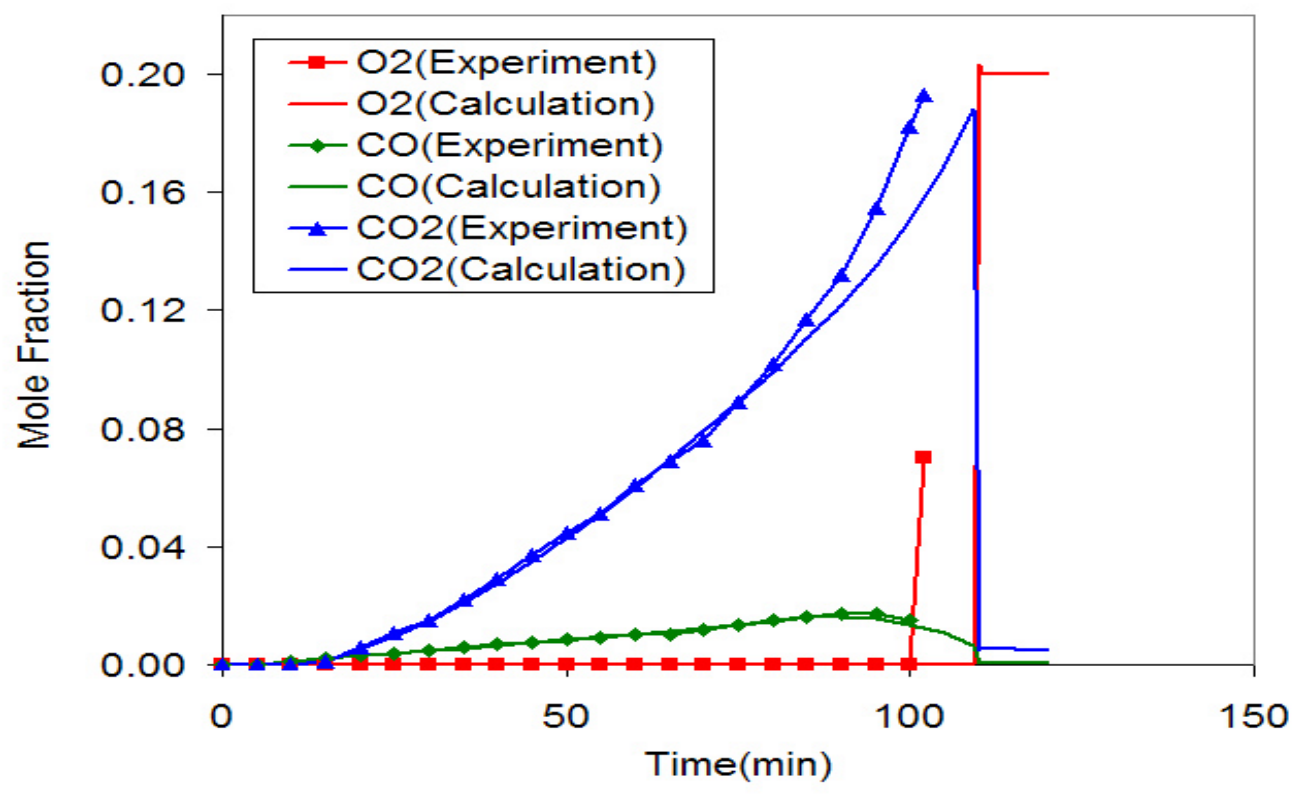

Figure 23: Mole Fraction at Point-3

At Point 4, on the cold leg, Figure 24 shows that the oxygen level initially increases due to cold leg diffusion but it is then reduced by the $\mathrm{CO}$ and $\mathrm{CO}_{2}$ gas mixture which diffuses to Point 4 . In addition, some of the oxygen reacts with the $\mathrm{CO}$ to form $\mathrm{CO}_{2}$ increasing its mole fraction while reducing the oxygen.

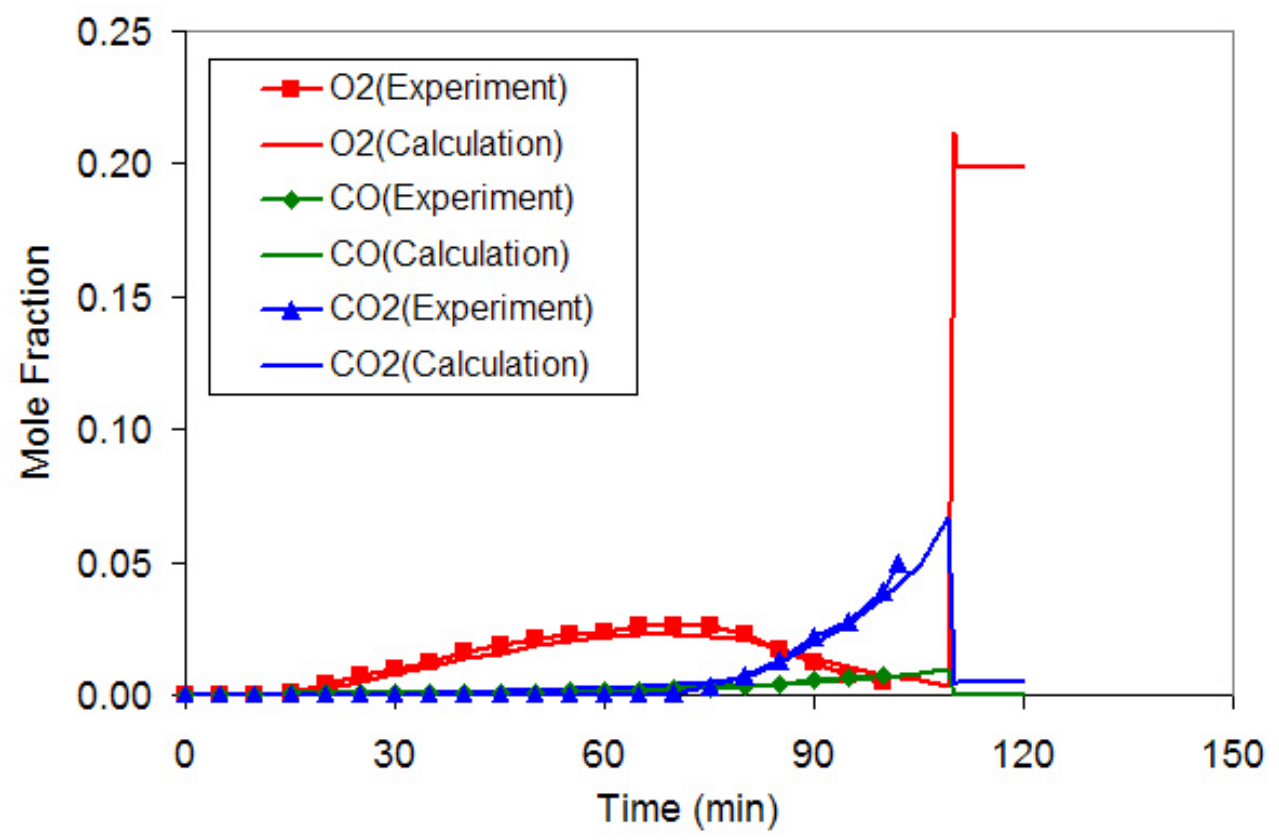

Figure 24: Mole Fractions at Point 4 
Once natural circulation starts, the dominate species is oxygen as shown on all figures with the concentrations of $\mathrm{CO}$ and $\mathrm{CO}_{2}$ dropping quickly and dramatically. During the natural circulation phase, the air ingress velocity is calculated to be $0.04 \mathrm{~m} / \mathrm{s}$. In addition, the graphite consumption rate shown on Figure 25 dramatically increases as expected to $2.3 \mathrm{E}-07 \mathrm{~kg} / \mathrm{s}$ from $1.3 \mathrm{E}-8 \mathrm{~kg} / \mathrm{s}$ during the diffusion process. This higher reaction rate is due to the surface chemical reaction rather than the volumetric diffusion reaction experienced during the diffusion stage. This is because the gas mixture moves at a higher velocity through the graphite pipe before it can diffuse into the graphite for the volumetric reaction.

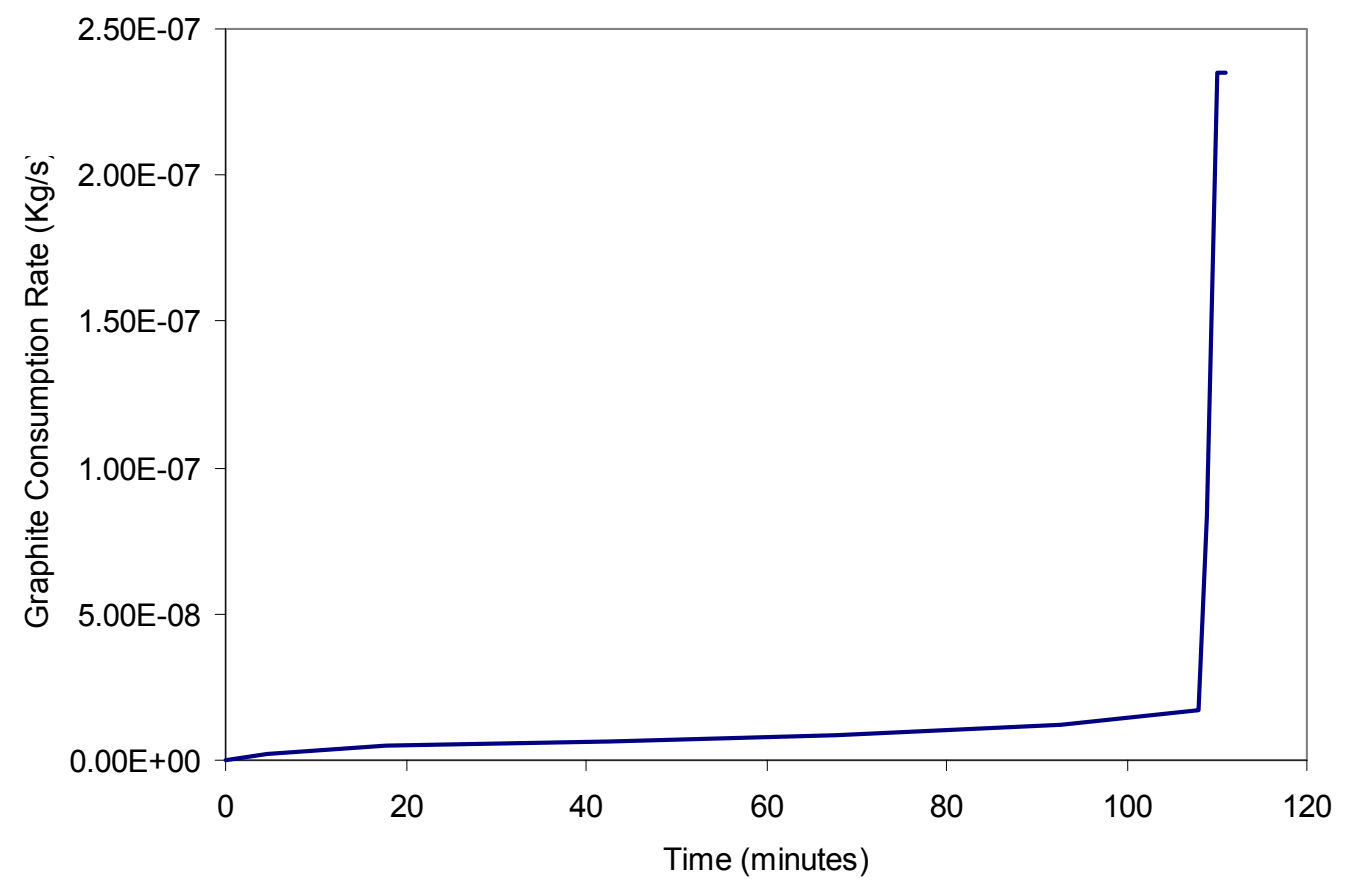

Figure 25: Graphite Consumption Rate (FLUENT6.0 calculation)

More important, through the CFD calculation, many critical points are identified for further numerical study on the air ingress accident:

- The ratios between the $\mathrm{CO}$ and $\mathrm{CO}_{2}$ on the graphite surface should be measured for the further CFD simulation.

- Besides the influence of the temperature, the roles played by graphite impurity should be studied carefully in the surface and the volume reactions.

- The reverse chemical reactions must be modeled in the dynamic processes (they are modeled in FLUENT model).

- The diffusion coefficients in the multi-component system are key parameters because they depend on the local concentration of all the gases involved, and the onset of the natural convection is mainly determined by the diffusion of the heavier gases.

In conclusion, natural circulation occurs in the multi-component experiment when the buoyancy produced by density difference between the hot and cold leg is high enough to overcome the 
friction in the flow path. Almost all the oxygen will be consumed in the diffusion stage, but in natural circulation stage, most of the oxygen will escape from the graphite pipe. Moreover, the dominant reaction production is $\mathrm{CO}_{2}$, not $\mathrm{CO}$ due to the rapid $\mathrm{CO}$ oxidation rate and high oxygen concentration, while most of the immediate product at the graphite surface is $\mathrm{CO}$.

\section{The NACOK Natural Convection Corrosion Experiment}

NACOK Natural Convection Corrosion experimental facility [Naturzug im Core mit Korrosion] at the Julich Research Center in Germany was built to study air ingress accidents in pebble bed reactors. There have been two significant air ingress tests performed at the facility. The first is a natural circulation flow test measuring mass flow rates at various hot and cold leg temperature through actual size ceramic pebbles. The second test was to an open chimney corrosion test simulating the lower reflector and smaller graphite pebbles [6]. Both tests are important research contributions to improved understanding of the unique characteristics of air flow in pebble bed reactors. The FLUENT code will be used to model the first series of mass flow tests.

\section{Experimental Apparatus}

The NACOK experimental facility is shown is schematically represented in Figure 26. The left square channel is called experiment channel, and the right pipe return pipe. The left channel, with $0.3 \mathrm{~m} \times 0.3 \mathrm{~m}$ square cross section, has a height of 7.3 meters, and the pebble bed with a height of 5 meters is installed in the experiment channel. The horizontal and the returning pipe have a diameter of 0.125 meter.



Figure 26: The Profile of the NACOK Experimental Apparatus [6]

In the mass flow experiment, forty individual runs in four series were made to study the features of the mass flow rates corresponding to the different temperature distributions in the experiments. For the first series of experiments, the temperature in the returning pipe is kept at $200{ }^{\circ} \mathrm{C}$ while the temperatures in the experiment channel are $250^{\circ} \mathrm{C}, 300^{\circ} \mathrm{C}, 350^{\circ} \mathrm{C}, 400^{\circ} \mathrm{C}, 450^{\circ} \mathrm{C}, 500^{\circ} \mathrm{C}$, 
$550^{\circ} \mathrm{C}, 600^{\circ} \mathrm{C}, 650^{\circ} \mathrm{C}, 700^{\circ} \mathrm{C}, 750^{\circ} \mathrm{C}, 800^{\circ} \mathrm{C}, 850^{\circ} \mathrm{C}, 900^{\circ} \mathrm{C}, 950{ }^{\circ} \mathrm{C}$ and $1000^{\circ} \mathrm{C}$ respectively. Similarly, for the second series of experiments, the temperature in the returning pipe is kept at $400{ }^{\circ} \mathrm{C}$ while the temperatures in the experiment channel are $450^{\circ} \mathrm{C}, 500^{\circ} \mathrm{C}, 550^{\circ} \mathrm{C}, 600^{\circ} \mathrm{C}$, $650^{\circ} \mathrm{C}, 700^{\circ} \mathrm{C}, 750^{\circ} \mathrm{C}, 800^{\circ} \mathrm{C}, 850^{\circ} \mathrm{C}, 900^{\circ} \mathrm{C}, 950^{\circ} \mathrm{C}$ and $1000^{\circ} \mathrm{C}$ respectively. Table 6 shows the temperatures for the experiment channel and the returning pipe.

Table 6: The Temperatures for the Experiment Channel and the Returning Pipe

\begin{tabular}{|l|l|l|}
\hline Series & $\begin{array}{l}\text { Average } \\
\text { temperature of the } \\
\text { Returning Pipe }\end{array}$ & Average wall temperature of the Experiment Channel \\
\hline 1 & 200 & $\begin{array}{l}250^{\circ} \mathrm{C}, 300^{\circ} \mathrm{C}, 350^{\circ} \mathrm{C}, 400^{\circ} \mathrm{C}, 450^{\circ} \mathrm{C}, 500^{\circ} \mathrm{C}, 550^{\circ} \mathrm{C}, \\
600^{\circ} \mathrm{C}, 650^{\circ} \mathrm{C}, 700^{\circ} \mathrm{C}, 750^{\circ} \mathrm{C}, 800^{\circ} \mathrm{C}, 850^{\circ} \mathrm{C}, 900^{\circ} \mathrm{C}, \\
950{ }^{\circ} \mathrm{C} \text { and } 1000^{\circ} \mathrm{C}\end{array}$ \\
\hline 2 & 400 & $\begin{array}{l}450^{\circ} \mathrm{C}, 500^{\circ} \mathrm{C}, 550^{\circ} \mathrm{C}, 600^{\circ} \mathrm{C}, 650^{\circ} \mathrm{C}, 700^{\circ} \mathrm{C}, 750^{\circ} \mathrm{C}, \\
800^{\circ} \mathrm{C}, 850^{\circ} \mathrm{C}, 900^{\circ} \mathrm{C}, 950^{\circ} \mathrm{C} \text { and } 1000^{\circ} \mathrm{C}\end{array}$ \\
\hline 3 & 600 & $650^{\circ} \mathrm{C}, 700^{\circ} \mathrm{C}, 750^{\circ} \mathrm{C}, 800^{\circ} \mathrm{C}, 850^{\circ} \mathrm{C}, 900^{\circ} \mathrm{C}, 950^{\circ} \mathrm{C}$ \\
& & $850^{\circ} \mathrm{C}, 9000^{\circ} \mathrm{C}$ \\
\hline 4 & 800 & $850^{\circ} \mathrm{C}$ and $1000^{\circ} \mathrm{C}$ \\
\hline
\end{tabular}

Compared with the lower laminar pressure loss in the return pipe and horizontal pipe, the pressure loss in the pebble bed region is much higher: Besides the much higher surface areas of the pebbles, the gas complicated flow path among the pebble lead to a higher form pressure loss. The pressure drop used in the pebble region is the pressure drop formula recommended by Julich Research Institue for this NACOK configuration [6]:

$$
\Delta P=-\frac{a}{\operatorname{Re} /(1-\varepsilon)}-\frac{b}{(\operatorname{Re} /(1-\varepsilon))^{0.1}}
$$

a: the coefficient for laminar pressure loss,

b: the coefficient for form pressure loss

$\mathrm{d}$ : the diameter of the pebbles

$\rho$ : the fluid density

$\eta$ : fluid dynamic viscosity

$\mathrm{u}$ : the gas velocity

$\varepsilon$ : the porosity of the pebble bed

This pressure drop could not defined directly in FLUENT, however, it could be converted into the following format from Eq. 25 .

$$
\Delta P=-C_{1} * \eta * u_{z}-C_{2} \rho^{0.9} * \eta^{0.1} * u_{z}^{1.9}
$$

where: 


$$
\begin{aligned}
& \mathrm{C}_{1}, \mathrm{C}_{2} \text { : constants } \\
& \eta \text { : fluid dynamic viscosity } \\
& \rho \text { : the fluid density } \\
& \mathrm{u}_{\mathrm{z}} \text { : the fluid velocity in z-coordinate direction }
\end{aligned}
$$

User Defined Function was developed to define the pressure drop (see [9]). In every iteration, the FLUENT server will access to the UDF to calculate the pressure drop using current and local thermal properties and velocity in $\mathrm{z}$ direction.

The structures and mesh generated using GAMBIT2.0 are shown in Figure 27. The total mesh number is 11,682 .
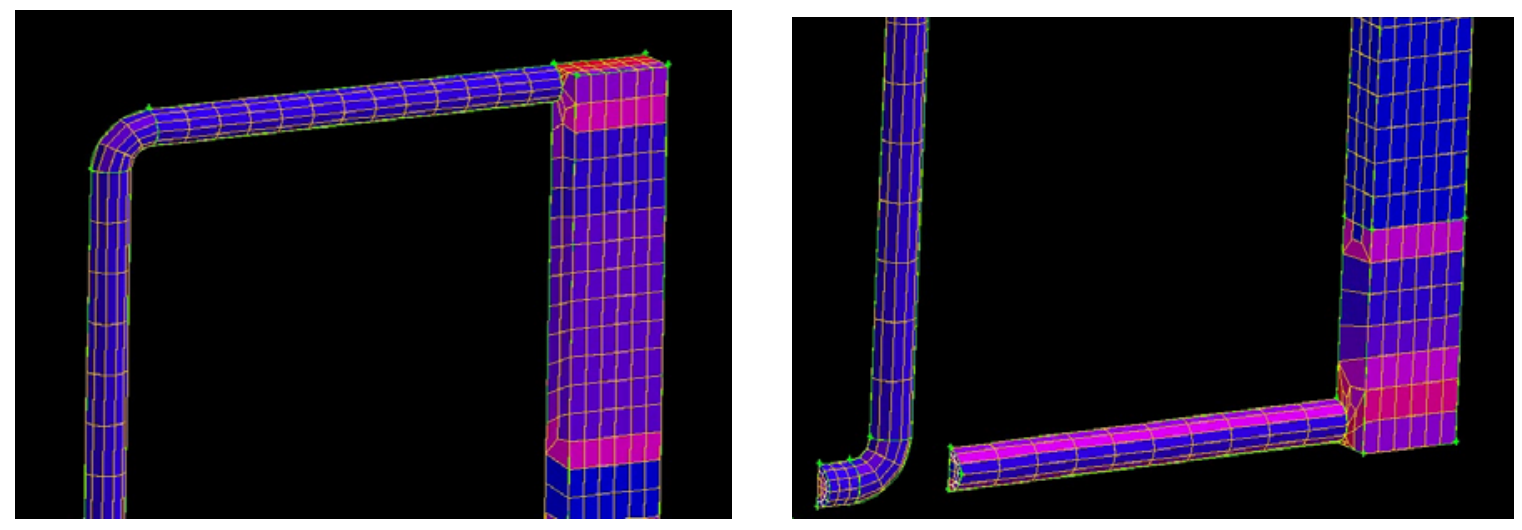

Figure 27: The Meshes Generated for the Top and Bottom

The conductivity, specific heat, density and viscosity of the air are defined accurately using 12 samples as a function of temperature. See [9] for a detailed model description on the NACOK experiment.

\section{Results and Conclusions}

Shown on Figure 28 are the mass flow rates predicted versus the experimental results for the four series of experiments. The FLUENT code as applied yields excellent agreement with experiment. In order to achieve such good results, the pressure drop equation (see Eq. 26) described above was benchmarked at a point (the experiment with $400{ }^{\circ} \mathrm{C}$ cold leg and $700^{\circ} \mathrm{C}$ hot leg) to calculate the friction loss constants ( $\mathrm{a}$ and $\mathrm{b}$ in Eq. 25) which was used for all subsequent experiments. Instead of the 505 used by the Germans in their analysis [6], 202 was found to be the appropriate constant. This adjustment was necessary since FLUENT calculates the laminar pressure loss on the channel wall automatically, the value of a should be lower than 505 in the UDF. 




Figure 27: Fluent Mass Flow Rate Comparisons with Experiment

In the experimental results, the mass flow rate decreases with the temperature increase in the returning pipe since the buoyancy would be reduced by the lower temperature difference between the cold leg and the hot leg. More importantly, the interesting result is that the mass flow rate not always increase with temperature increase in the experiment channel. Actually, in the former theoretical analysis, these results were predicted.

In conclusion, the FLUENT code with appropriate understanding of the experimental configuration and how FLUENT actually performs its analysis, has been shown to represent the natural steady state circulation in a pebble bed in a large range of hot and cold leg temperature differences. This capability will be applied to future modeling of the NACOK experiments in which air, a reflector and graphite pebbles will be introduced.

\subsection{Conclusions and Future Work}

The objective of this analysis was to develop a better understanding of the details of air ingress accidents in pebble bed and prismatic reactors. A theoretical study of an open cylinder of pebbles to better understand the key processes involved in air ingress was performed using the previous results from the LOCA analysis as initial conditions. The HEATING-7 model with side calculations to model the buoyancy and resistance to flow in a pebble was used to predict the peak fuel temperatures and air ingress velocity. The results of this simple analysis showed that 
that heat source contribution from the chemical reaction was relatively low and confined to the lower reflector region. The peak temperature increase from the non-chemical LOCA analysis was about $21{ }^{\circ} \mathrm{C}$ (a maximum of $1663{ }^{\circ} \mathrm{C}$ at 92 hours). The other interesting result was that the air ingress velocity decreased after about $350{ }^{\circ} \mathrm{C}$. This negative feedback could be a significant factor in air ingress accidents in real reactors since the average post LOCA temperature in the reactor is on the order of $1300{ }^{\circ} \mathrm{C}$.

Using these fundamental insights, attention was then focused on developing a benchmarked computational fluid dynamics modeling capability for air ingress events. Two series of tests were used to benchmark the CFD code selected for this analysis - FLUENT 6.0. The first series of tests were performed at the Japan Atomic Energy Research Institute (JAERI). These tests were aimed at understanding the fundamental processes of air ingress accidents in separate effects tests. There are initial diffusion, natural circulation and the chemical reactions with heated graphite in a prismatic reactor configuration. The FLUENT model and methodology developed was able to predict each of these tests quite well.

The second experimental benchmark was the Juelich Research Center test performed at the NACOK facility. This series of tests was to model natural circulation in a pebble bed reactor under varying hot and cold leg temperatures to assess air mass flow rate. The FLUENT methodology developed was able to predict the mass flow rates for the 40 experiments with very good results. This work will be used to benchmark the NACOK chemical corrosion tests in the future. A outline for the work plan for continuation of this work has been prepared for development of a benchmarked CFD capability to analyze the details of air ingress accidents for real reactors.

\subsection{References:}

[1] FLUENT Inc. 2002, "FLUENT 6.0 User's Guide"

[2] FLUENT Inc. 2002, "GAMBIT 2.0 User's Guide”

[3] Hishida, M., and T. Takeda, 1991. "Study on air ingress during an early stage of a primarypipe rupture accident of a high-temperature gas-cooled reactor," Nuclear Engineering and Design, $126,175-187$.

[4] Takeda, T., and M. Hishida, 1992. "Studies on diffusion and natural convection of twocomponent gases," Nuclear Engineering and Design, 135, 341-354.

[5] Takeda T. and Hishida, M., "Studies on molecular diffusion and natural convection in a multicomponent gas system," Int. J. Heat Mass Transfer", Vol. 39, No. 3, pp. 527-536, 1996.

[6] Kuhlmann, M. B., "Experiments to investigate flow transfer and graphite corrosion in case of air ingress accidents in a high-temperature reactor". 1999. 
[7] Rehm, W., W. John, and K. Verfondern, 1988. "Present Results and Further Developments on Safety Analysis of Small and Medium-Sized HTRs for Core Heat-Up Accidents," Nuclear Engineering and Design 109, pp. 281-287.

[8] Tang, Chunhe, Guan, Jie, "Improvement in oxidation resistance of the nuclear graphite by reaction-coated $\mathrm{SiC}$ coating”, Institute of Nuclear Energy Technology, Tsinghua University.

[9] Zhai, Tieliang, "LOCA and Air Ingress Accident Analysis of a Pebble Bed Reactor", Engineering Degree Dissertation, August 2003, Massachusetts Institute of Technology, Nuclear Engineering Department.

[10] Yang, S., "Heat Transfer", second edition, Beijing, 1989

[11] Oh, C., Merrill, B., Moore, R., and D. Petti, January, 2001, "Oxidation Model for a MPBR Graphite Pebble,” Idaho National Engineering \& Environmental Laboratory.

[12] Fenech, Henri, "Heat Transfer and Fluid Flow in Nuclear Systems", Pergamon Press, 1980, P382-401

[13] Yan, Xinglong, June, 1990, "Dynamic Analysis and Control System Design for an Advanced Nuclear Gas Turbine Power Plant". MIT Ph.D thesis.

[14] Bird, R. B., W. E. Stewart, and E. N. Lightfoot, 1960, Transport Phenomena, John Wiley and Sons, New York, p. 269. 